\title{
Metodología para la Medición del Déficit Cualitativo de Espacio Público en Colombia: un Indicador Clave del Ordenamiento Territorial
}

\author{
Methodology for Measuring the Qualitative Deficit in Public Space in Colombia: \\ A key Indicator in Land use Planning
}

Juan Eduardo Jiménez Caldera ${ }^{1}$

Rosana Garnica Berrocal ${ }^{2}$

Recibido: 25 de julio de 2016

Aceptado: 28 de diciembre de 2016

\section{Resumen}

En este artículo se propone una metodología para la evaluación del "déficit cualitativo del espacio público", en respuesta a los vacíos y debilidades que presenta la normatividad colombiana. Se centra en la valoración individual del estado cualitativo de los diversos elementos del espacio público (escenarios deportivos, infantiles y de estancia de escala o influencia vecinal, zonal o regional), permitiendo su representación espacial y la realización de análisis territoriales, en el marco del proceso de planificación y ordenamiento territorial. El caso de estudio aplicado en la ciudad de Montería, Colombia, valida el funcionamiento de la metodología, evidenciando la afectación de la calidad de vida de los ciudadanos a causa de las inadecuadas condiciones físico-espaciales que no garantizan la funcionalidad del espacio público.

Palabras clave: Colombia, déficit cualitativo, espacio público, planificación y ordenamiento territorial.

\begin{abstract}
This research proposes a methodology for the evaluation of the "qualitative deficit of the public space", in response to the gaps and weaknesses presented by Colombian regulations. It focuses on the individual assessment of the qualitative state of the various elements of the public space (sports, children and residence scales of influence or neighborhood, zonal or regional influence scenarios), allowing its spatial representation and territorial analysis in the framework of the planning process and land use planning. The case study applied in the city of Monteria, Colombia, validates the operation of the methodology, evidencing the affectation of the quality of life of the citizens due to the inadequate conditions that do not guarantee the functionality of the public space.
\end{abstract}

Key words: Colombia, planning and territorial ordering, public space, qualitative deficit.

\footnotetext{
1 Universidad de Córdoba, Departamento de Geografía y Medio Ambiente, Programa de Geografía, Montería, Colombia. Contacto: juanjimenezc@correo.unicordoba.edu.co

2 Universidad de Córdoba, Departamento de Geografía y Medio Ambiente, Programa de Geografía, Montería, Colombia. Contacto: rgarnica@correo.unicordoba.edu.co
} 


\section{Introducción}

La función que tiene el espacio público de favorecer la calidad de vida urbana se cumple en primera instancia cuando en la ciudad existen condiciones físicas y espaciales que garantizan el uso, goce y disfrute de cada uno de sus elementos constitutivos (parques, plazas, áreas verdes, rondas, escenarios deportivos, entre otros) (Martí, García y Nolasco, 2013). Tales condiciones hacen referencia a la disponibilidad de espacios destinados al esparcimiento, la recreación y el encuentro de los ciudadanos (Inzulza-Contardo \& Cruz, 2014); a su distribución equitativa en el territorio; a la diversidad que debe tener para satisfacer los intereses y gustos de cada individuo y al estado físico de sus componentes internos.

De acuerdo con lo planteado por el Ministerio de Vivienda, Ambiente y Desarrollo Territorial (2004), el ordenamiento territorial en Colombia considera el espacio público como un aspecto clave que incluye la definición, delimitación y clasificación de los elementos constitutivos (naturales, artificiales y complementarios) en diferentes escalas (territorial y urbana), así como de los subsistemas que complementan el sistema general (redes peatonales, parques, entre otros); también, la definición de proyectos y programas estratégicos de acuerdo con las necesidades y desequilibrios, la generación de espacio público basado en las normas urbanísticas (cesiones y parámetros para garantizar su integración a los planes parciales); los déficit cuantitativo y cualitativo, de los cuales solo en el primero se deja claro su medición.

Por su parte, según la Política Nacional de Espacio Público adoptada por el Consejo Nacional de Política Económica y Social (Conpes, 2012) 3718, uno de los vacíos y debilidades en torno al tema del espacio público en Colombia es la nula y escasa aplicación de instrumentos metodológicos para planear, ordenar y diseñar dichos espacios. Esta considera que el tratamiento del espacio público a través de los instrumentos de planeación y gestión originados en la Ley 388 de 1997 ha sido residual, fragmentado, sin parámetros claros de ordenación y la ausencia de dotación de mobiliarios y equipamientos adecuados.

En razón de lo anterior, es necesario reflexionar respecto de cómo se está planeando y ordenando el espacio público en las ciudades, a partir de la existencia o no de directrices y lineamientos metodológicos que trasciendan el cálculo de indicadores estipulados en la normatividad vigente, principalmente lo establecido en el Decreto 1504 de 1998 en lo referido a la definición del espacio público, los déficit cuantitativo y cualitativo; la clasificación de los elementos que lo constituyen (naturales, artificiales y complementarios), entre otros aspectos que no permiten conceptualizar y operacionalizar a través de metodologías que evalúen las condiciones físico-espaciales del mismo. 
La anterior situación se ilustra con lo señalado por Saldarriaga (2005) quien alude a que la meta alcanzable de los $10 \mathrm{~m}^{2}$ por habitante es solo una referencia, pues es un indicador que "no dice mucho acerca de la calidad del espacio público ni de su distribución equitativa en el territorio de la ciudad. Tampoco dice mucho acerca de su relación con la vivienda o con el resto de las actividades urbanas", denominado déficit cuantitativo que evalúa la proporción de espacio público respecto del número de habitantes, cuya aplicación es un requisito exigido en la normatividad; pese a la incertidumbre evidente, este indicador en la actualidad se ha convertido en el principal insumo empleado en los procesos de planeación del espacio público.

Igualmente, en lo que al déficit cualitativo se refiere, se reconoce como una debilidad la manera en que es abordado en los instrumentos de planificación territorial. Según la Política Nacional de Espacio Público:

... en Colombia no se ha desarrollado un estudio de diagnóstico que permita revelar la situación actual del déficit cualitativo de espacio público. En gran medida, el balance nacional y de las ciudades es perceptivo y se plantea sobre la base de las carencias de mobiliario, señalización, iluminación y zonas verdes; como también, deficiencias en el diseño, tratamiento de superficies (zonas duras y blandas), circulación y estacionamientos, inseguridad, entre otros (Conpes, 2012, pp. 9-10).

Las condiciones físico-espaciales que garantizan el uso, goce y el disfrute de los elementos del espacio público, entendidas estas a partir de su diversidad (presencia escenarios deportivos, estancia e infantiles) para satisfacer los intereses y gustos de los ciudadanos y de su grado de distribución en el territorio, no se consideran como variables o elementos de análisis clave en los planes de ordenamiento territorial municipal para evaluar la situación del espacio público en las ciudades. Por tal razón, es cuestionable la calidad de los diagnósticos territoriales realizados en el marco de la planificación urbana que se vienen implementando desde el año 1998 en Colombia a partir de la promulgación de la Ley de Desarrollo Territorial (388 de 1997), que en su artículo $1^{\circ}$ reglamenta entre sus objetivos velar por la creación y la defensa del espacio público, y en el artículo $13^{\circ}$, la localización de espacios libres para parques y áreas verdes públicas en proporción a las necesidades colectivas, teniendo como antecedente la Ley 9 de 1989 (Reforma Urbana).

La Ley de Reforma Urbana se refiere en el capítulo II al espacio público, definiéndolo define como los inmuebles públicos y los elementos arquitectónicos y naturales de los inmuebles privados, destinados a la satisfacción de necesidades urbanas colectivas que superan los límites de los intereses, individuales de los habitantes. 
En un intento por establecer directrices acerca de cómo planear y ordenar el espacio público articulador, de intercambio y encuentro ciudadano (Decreto 1504 de 1998), en contribución a los procesos de ordenamiento territorial municipal de Montería, se han llevado a cabo dos estudios que incorporan el análisis espacial como herramienta para la comprensión de la realidad urbana, a fin de efectuar una evaluación objetiva de sus atributos a partir de la medición cualitativa y cuantitativa de las condiciones físico-espaciales del espacio público. El primero fue realizado por Jiménez en el año 2009 y se titula Espacio público y calidad de vida urbana: análisis de las condiciones físicoespaciales en la ciudad de Montería, mientras que el segundo, fue realizado por Garnica y Jiménez en el 2013 bajo el nombre La calidad de vida urbana y la dimensión físico-espacial del espacio público: aportes metodológicos para el ordenamiento territorial de Montería.

Por un lado, el primer estudio plantea por primera vez la clasificación del espacio público según su composición y la función que presta a la sociedad de acuerdo con la escala o área de influencia, a partir del Decreto 1504. De igual modo, se realiza allí una primera aproximación a la valoración del déficit cualitativo, dando cuenta de las condiciones mínimas requeridas y las malas generadoras de este. Por otro lado, el segundo trabajo, perfecciona una de las técnicas de análisis y modelamiento espacial empleado en la medición de la accesibilidad peatonal, la que estima el nivel de acceso al espacio público en función de la distancia recorrida a pie.

Se parte de la hipótesis de que la valoración de las condiciones cualitativas del espacio público mediante el cálculo del déficit cualitativo, demuestra la satisfacción o insatisfacción de las necesidades de los ciudadanos, lo cual incide en la calidad de vida urbana al permitir el desarrollo de diferentes actividades recreativas, deportivas, de encuentro e intercambio.

En este contexto, se ha diseñado una propuesta metodológica para fortalecer el análisis del déficit cualitativo del espacio público en los planes de ordenamiento territorial, convirtiéndose en un instrumento que da soporte a los procesos de toma de decisiones en el ámbito de la planificación y el ordenamiento de las ciudades. Su elaboración se apoya, en primera instancia, en la precisión de las condiciones mínimas requeridas para que no exista déficit, tomando como base la normatividad existente y la clasificación de espacio público según la composición y función que presta a la sociedad (escenarios deportivos, infantiles y de estancia); y también, según el área de influencia que puede presentar (vecinal, zonal y regional). $Y$, en segunda instancia, en el diseño de un formato de recolección de datos in situ que permite valorar, una a una, las condiciones generadoras de déficit en un elemento del espacio público, así como su evaluación global mediante una fórmula. 
El formato de recolección de datos in situ tiene en cuenta los cuatro aspectos esenciales que garantizan la funcionalidad el espacio público:

- el primero es de índole ambiental y se asocia a la arborización (sombra);

- el segundo, trata de los diferentes tipos de invasión (vehicular, ventas informales, prestación de servicios y basuras);

- el tercero se refiere al estado del mobiliario urbano (bancas, luminarias peatonales, canecas ${ }^{3}$, señalización, juegos infantiles, juegos para adultos, bicicleteros y baños públicos), y particularmente para los escenarios deportivos el estado de las gradas, del campo o terreno y de los componentes principales según sea el deporte (arcos, mallas, aro, pista, entre otros); y

- el cuarto, trata la existencia y necesidad de la disposición de planes generales para la creación, potenciación y reparación.

Las condiciones generadoras de déficit cualitativo en el espacio público se evalúan una vez que se logra verificar en terreno la existencia de los aspectos y su estado físico. Este procedimiento consiste en una valoración subjetiva que efectúa el personal que inspecciona ocularmente cada elemento del espacio público (puede ser un operario de campo delegado por la administración municipal o la comunidad usuaria), sobre el mobiliario y otros componentes internos que lo conforman. La información registrada en la tabla o formato de recolección de datos facilita el cálculo de un porcentaje de déficit cualitativo, a partir de una fórmula que depende de la relación de proporción entre las malas condiciones generadoras de déficit y las condiciones mínimas requeridas para que no exista el mismo, siendo estas últimas establecidas en la normatividad.

Mediante la determinación del porcentaje de déficit cualitativo se puede realizar la representación espacial de esta variable en el territorio, posibilitando la elaboración de análisis orientados a la focalización de áreas dentro de la ciudad, donde la calidad de vida urbana está siendo afectada por el mal estado del espacio público. También ayuda a identificar aquellos espacios que, a pesar de encontrarse en buen estado físico, están expuestos a presión o sobreutilización, acelerando su deterioro. Igualmente, posibilita la priorización de las intervenciones en los diferentes elementos constitutivos del espacio público por parte de los actores (sociales, instituciones, económicos, entre otros) y la articulación e integración con instrumentos de planificación urbana y territorial como planes de ordenamiento territorial, planes especiales de equipamientos y espacio público, planes maestros de espacio públicos, entre otros.

\footnotetext{
${ }^{3}$ En Colombia, un cubo o lata para la basura.
} 
El caso de estudio aplicado en el occidente de ciudad de Montería, Colombia, permitió validar la metodología en una de las áreas con niveles socioeconómicos bajos, mayor concentración poblacional entre $12.816,1$ y $13.312,1 \mathrm{hab} / \mathrm{Km}^{2}$, y en procesos de crecimiento urbano formal e informal (Garnica, 2009), evidenciando que la calidad de vida urbana se puede estar viendo afectada por las inadecuadas condiciones cualitativas para ejercer la práctica de actividades recreativas y de esparcimiento. La representación espacial del déficit cualitativo muestra los sectores donde puede existir presión por la sobreutilización de espacio público, específicamente donde están concentrados los pocos escenarios en calidad aceptable o en buen estado. También se evidencia que los espacios con bajo déficit son insuficientes para satisfacer las necesidades e intereses de la cantidad de población residente.

\section{Fundamentos conceptuales y metodológicos}

Según Giraldo (1989), la ciudad se entiende como un producto físico, una concentración de poblaciones y de actividades, una mezcla social y funcional con capacidad de autogobierno y ámbito de participación simbólica y de participación cívica (Inzulza-Contardo, 2014; Stephens, 2010). La ciudad entendida como un fenómeno espacial en el cual tienen lugar las expresiones culturales y la construcción social de la ciudadanía, requiere de la existencia del espacio público, dada su importancia en la generación de la calidad de vida y convivencia ciudadana (Monnet, 2000; Páramo y García, 2010).

Es así como Páramo (2007) afirma que la calidad de vida en la ciudad se valora como buena o mala de acuerdo con las experiencias que los individuos tengan en relación con los "otros", evitando el aislamiento social, sintiéndose parte de la ciudad e integrándose con los demás en la sociedad (Shurch, 1999).

La calidad de vida urbana se manifiesta de forma favorable en las ciudades, entre otros aspectos, siempre que existan mínimas condiciones físicas y espaciales que garanticen el uso y disfrute del espacio público, como el buen estado de los componentes que lo conforman, la suficiencia y distribución equitativa de sus elementos en el territorio, la forma en que deberían constituirse (escenarios deportivos, de estancia e infantiles), sin desconocer su utilización por parte de los diferentes usuarios (niños, jóvenes, adultos, ancianos), quienes representan la diversidad de intereses y preferencias al momento de satisfacer sus necesidades (Garnica y Jiménez, 2013).

Al respecto, Daza (2008) indica que el espacio público es un elemento articulador de la existencia de la ciudad tanto en el plano físico-funcional como en el simbólico-interpretativo. La naturaleza de lo urbano sobrepasa la visión de lo idílico y reconoce la existencia de realidades culturales, sociales, económicas y de identidad, de quienes habitan el territorio (Sequera y Janoschka, 2012). Es así que la vivencia de lo urbano lleva a la interacción de 
atributos y dimensiones, en los cuales el espacio público se constituye en un escenario de referencia y posibilidad de articulación.

Igualmente, el espacio público es de dominio público, uso colectivo y multifuncionalidad (Hebbert, 2005). Físicamente se caracteriza por su accesibilidad, que lo convierte en factor de centralidad y su calidad se puede evaluar principalmente por la intensidad y la calidad de las relaciones sociales posibles para diversos grupos, lo que hace necesario que el mismo disponga de calidades formales (Borja y Muxi, 2000).

Para estos autores el espacio público impone tres desafíos en la política urbana, como son el urbanístico, político y cultural, entendiéndose el primero a partir de la función ordenadora del urbanismo debido a que debería organizar un territorio que soporte diversidad de usos y funciones; y crear lugares de la diferenciación y articulación de la ciudad. El segundo, como espacio de la expresión colectiva, la vida comunitaria, del encuentro, intercambio cotidiano, de las afirmaciones y confrontaciones ciudadanas. El tercero, implica responder a los gustos y aspiraciones de diferentes sectores poblacionales más allá de la función específica de dicho espacio.

Asimismo, Carmona, Health, Oc y Tiesdell (2003) plantean que el espacio público se puede observar, analizar y evaluar a partir de seis dimensiones:

a) Morfológica, definida por la configuración urbana de la arquitectura, los usos del suelo, la red vial y de espacio público.

b) Perceptual, por el significado y el simbolismo otorgado al entorno construido, los sentidos de lugar.

c) Social, entendida por las nociones de accesibilidad, barrio, seguridad, relaciones entre espacio y sociedad.

d) Visual, entendida desde las preferencias y cualidades estéticas.

e) Funcional, concebida desde los usos del espacio público, los aspectos de densidad y multifuncionalidad, por el diseño del entorno.

f) Temporal, teniendo en cuenta los ciclos temporales y los tiempos de las actividades, los diferentes tiempos entre políticas y proyectos de diseño urbano, entre otras consideraciones en cada dimensión (Carmona et al., 2003).

Sumado a lo anterior, Páramo plantea la idea de que "el ambiente espacial es un componente que facilita la integración y la comunicación entre los ciudadanos; el mobiliario urbano, la existencia de parques, las plazas, los lugares de encuentro y socio-lugares, la vegetación, etc., elementos que actúan como oportunidades para los encuentros sociales que contribuyen a la creación de tejido social" (Páramo, 2007, p. 24). En este sentido, la presente investigación acerca de las condiciones físico-espaciales del espacio público tiene en cuenta como variables de estudio los elementos antes mencionados a los que cabe adicionar el grado de distribución de los mismos. 
Las condiciones físico-espaciales del espacio público en las cuales se centra esta investigación aluden a la medición del déficit cualitativo como uno de los indicadores de calidad de vida que refleja el estado de los elementos de estos espacios, determinando su uso para el goce y disfrute asociados con la recreación activa y pasiva y reflejando, principalmente, las condiciones de deterioro e imposibilidad física para su acceso.

Los cuatro aspectos abordados en la evaluación de dicho déficit se basan en el contenido del Decreto 1504 de 1998 (artículo 5, numeral 2, inciso $b$ acerca de áreas articuladoras de espacio público y de encuentro; y el artículo $13^{\circ}$ que define el déficit cualitativo). Las condiciones mínimas requeridas para que no exista déficit cualitativo se extrajeron de la normatividad $y$, posteriormente, fueron precisadas para cada tipo de espacio público, de acuerdo con la clasificación de su composición y función, y también según la escala o área de influencia, definidas por Garnica y Jiménez (2013), como se muestra a continuación en las Tablas 1 y 2 . Dichas tipificaciones, permiten reclasificar e integrar en menos categorías y más estandarizadas, las tipologías de espacio público existentes en el ambiente urbano (parques, zonas verdes, plazas, plazoletas, rondas hídricas, canchas deportivas, entre otros), facilitando así la precisión de las condiciones mínimas requeridas para la determinación del déficit.

Cabe resaltar que, de acuerdo con la clasificación asignada, entre un elemento del espacio público y otro puede variar el número de condiciones mínimas requeridas para su valoración cualitativa. Por ejemplo, en un escenario deportivo no se evalúa la presencia de sombra por arborización, pero sí se cuenta para un escenario de estancia e infantil. Un escenario de escala o influencia vecinal no requiere de baño público y bicicletero, pero sí es necesario en escenarios los zonales y regionales.

Tabla 1

Clasificación del espacio público de articulación y encuentro ciudadano existentes en el según su composición

\begin{tabular}{|c|l|l|}
\hline $\begin{array}{c}\text { Clasificación del } \\
\text { espacio público } \\
\text { según su } \\
\text { composición }\end{array}$ & Función & \multicolumn{1}{|c|}{ Descripción } \\
\hline Escenarios deportivos & $\begin{array}{l}\text { Ocio } \\
\text { recreación } \\
\text { activa }\end{array}$ & $\begin{array}{l}\text { Superficie destinada únicamente al } \\
\text { ejercicio de la actividad deportiva de } \\
\text { la comunidad en general (canchas de } \\
\text { fútbol, baseball, basquetbol, tejo, } \\
\text { etc.). }\end{array}$ \\
\hline
\end{tabular}




\begin{tabular}{|c|c|c|c|}
\hline Escenarios infantiles & & & $\begin{array}{l}\text { Superficie que, por sus elementos } \\
\text { constituyentes (equipamiento infantil } \\
\text { tales como columpios, subibajas, } \\
\text { etc.), está destinada únicamente al } \\
\text { ejercicio de la actividad recreativa } \\
\text { para niños. }\end{array}$ \\
\hline Escenarios de estancia & $\begin{array}{l}\text { Ocio, } \\
\text { recreación } \\
\text { pasiva, } \\
\text { reunión } \\
\text { armonía }\end{array}$ & $y$ & $\begin{array}{l}\text { Superficies constituidas por aspectos } \\
\text { ambientales como árboles (suministro } \\
\text { de sombra), césped y está dotado con } \\
\text { mobiliario (bancas); destinado para el } \\
\text { ejercicio de la actividad pasiva } \\
\text { (descanso y la armonía de la población } \\
\text { en general.) }\end{array}$ \\
\hline \multicolumn{4}{|c|}{$\begin{array}{l}\text { Es posible encontrar elementos del espacio público con presencia de dos o tres } \\
\text { de los escenarios, lo que se conoce como espacio público diverso. Entre más } \\
\text { composiciones tenga un elemento (tres como máximo) se considera más } \\
\text { diverso dicho espacio. }\end{array}$} \\
\hline $\begin{array}{l}\text { Espacio público } \\
\text { compuesto por } \\
\text { escenarios deportivos } \\
\text { y parques infantiles }\end{array}$ & \multirow{4}{*}{\multicolumn{2}{|c|}{$\begin{array}{l}\text { Ocio, } \\
\text { recreación } \\
\text { activa } \\
\text { pasiva, } \\
\text { reunión } \\
\text { armonía }\end{array}$}} & $\begin{array}{l}\text { Superficie multifuncional, destinada a } \\
\text { la recreación infantil y a la práctica de } \\
\text { la actividad deportiva. }\end{array}$ \\
\hline $\begin{array}{l}\text { Espacio público } \\
\text { compuesto por } \\
\text { espacios verdes de } \\
\text { estancia y parques } \\
\text { infantiles }\end{array}$ & & & $\begin{array}{l}\text { Superficie multifuncional, destinada a } \\
\text { la recreación infantil, al descanso y a } \\
\text { la armonía de la población en general. }\end{array}$ \\
\hline $\begin{array}{l}\text { Espacio público } \\
\text { compuesto por } \\
\text { espacios verdes de } \\
\text { estancia y escenarios } \\
\text { deportivos }\end{array}$ & & & $\begin{array}{l}\text { Superficie multifuncional, destinada a } \\
\text { al descanso, la armonía de la } \\
\text { población en general y a la práctica de } \\
\text { la actividad deportiva. }\end{array}$ \\
\hline $\begin{array}{l}\text { Espacio público } \\
\text { compuesto por } \\
\text { espacios verdes de } \\
\text { estancia, parques } \\
\text { infantiles y escenarios } \\
\text { deportivos }\end{array}$ & & & $\begin{array}{l}\text { Superficie multifuncional, destinada a } \\
\text { la recreación infantil, al descanso y la } \\
\text { armonía de la población en general y a } \\
\text { la práctica de actividades deportivas. }\end{array}$ \\
\hline
\end{tabular}

Fuente: Garnica y Jiménez (2013). 
Tabla 2

Clasificación espacio público de articulación y encuentro ciudadano existentes en el según su escala

\begin{tabular}{|c|l|}
\hline $\begin{array}{c}\text { Clasificación } \\
\text { según escala }\end{array}$ & \multicolumn{1}{|c|}{ Descripción } \\
\hline Regional & $\begin{array}{l}\text { Son espacios de gran dimensión y altos valores ambientales, } \\
\text { que satisfacen necesidades de la población local y de otras } \\
\text { localidades distantes. }\end{array}$ \\
\hline Zonal & $\begin{array}{l}\text { Áreas o espacios libres, con una dimensión variable, } \\
\text { destinada a la satisfacción de necesidades de recreación } \\
\text { activa y/o pasiva de un grupo de barrios. }\end{array}$ \\
\hline Vecinal & $\begin{array}{l}\text { Áreas o espacios libres, destinados a la recreación, la } \\
\text { reunión y la integración de la comunidad, que cubren } \\
\text { necesidades de barrios. Se les domina genéricamente } \\
\text { parques, zonas verdes o cesiones para parques. El parque } \\
\text { de bolsillo es una modalidad de parque vecinal, que tiene un } \\
\text { área inferior a 1.000 m² y está destinado exclusivamente a } \\
\text { la recreación pasiva contemplativa. }\end{array}$ \\
\hline
\end{tabular}

Fuente: Garnica y Jiménez (2013).

La determinación del déficit cualitativo. Una vez que se han clasificados los elementos del espacio público según su composición y función, y también según la escala o área de influencia, se procede a determinar el déficit cualitativo de espacio público, teniendo como primer aspecto a evaluar el ambiental asociado a la arborización (sombra), considerándose la vegetación como elemento generador de microclimas que inciden en el comodidad de los ciudadanos en lo que se refiere a la temperatura. Investigadores afirman que en los espacios públicos la calidad, cantidad y forma de uso son determinadas en gran parte por las condiciones de clima. La existencia de vegetación es considerado un aspecto importante en dos escenarios de espacio público como son los de estancia y los infantiles, dada la función y usos sociales que estos prestan como caminar, conversar, contemplar y observar el paisaje y descansar (recreación pasiva), entre otros. En este aspecto se evalúa la existencia o no de sombra a partir de la vegetación arbórea existente.

En el segundo aspecto, la invasión, referida a la función social pública y al carácter jurídico del dominio público del espacio público (Garriz y Schroeder, 2014), lo que lleva a pensar en:

... la separación formal (legal) entre la propiedad privada urbana ... y la propiedad pública (o dominio público por subrogación normativa o por adquisición de derecho mediante cesión) que supone reservar este suelo libre de construcciones (excepto equipamientos colectivos y servicios 
públicos) y cuyo destino son usos sociales característicos de la vida urbana (Borja, 1998, p. 13).

Lo anterior lleva a destacar que bajo estas ideas ningún espacio público debería tener algún tipo de invasión (vehicular, ventas informales, prestación de servicios y basuras) que limite, restrinja e imposibilite su uso, disfrute y goce.

En el tercer aspecto referido al estado del amoblamiento urbano, visto como un elemento complementario del espacio público en relación con la ambientación (bancas, luminarias peatonales), los servicios (bicicleteros), la recreación (módulo y juegos para adultos e infantiles), salud e higiene (baños públicos, canecas) y señalización. Es de anotar que según el tipo de escenario se considera la necesidad del tipo de mobiliario. Particularmente, el amoblamiento urbano de los escenarios deportivos deberá tener en cuenta el estado de las gradas, del campo o terreno y de los componentes principales según sea el deporte (arcos, mallas, aro, pista, entre otros).

En el cuarto y último aspecto, los planes generales para la creación, potenciación y reparación, que tratan sobre los instrumentos de planificación y gestión urbana que garantizan el buen funcionamiento del espacio público, deberá ser incluida la generación, el mejoramiento, la adecuación y la proyección de nuevos usos de acuerdo a las dinámicas urbanas.

Metodológicamente, el déficit cualitativo del espacio público es el resultado de la relación entre la condiciones generadoras de déficit y las mínimas requeridas para evaluar el estado de uno de los elementos constitutivos, las cuales dependen de su composición individual (escenarios infantiles, deportivos y de estancia) y diversa con la combinación de las anteriores (Tabla 1) y de la escala o influencia vecinal, zonal y regional (Tabla 2). Las dos últimas escalas, al demandar el mayor número de usuarios procedentes de distintos sectores de la ciudad y externos a la misma, requieren de baños públicos y bicicleteros, dada la permanencia de ellos durante su visita.

El déficit cualitativo del espacio público se calcula mediante la siguiente fórmula: $\mathrm{DC}=(\mathrm{CGDC} / \mathrm{CMR}) \times 100$, donde $\mathrm{CGDC}$ son las condiciones generadoras de déficit y CMR las condiciones mínimas requeridas (Tabla 3), teniendo en cuenta que las primeras se evalúan a través de la ausencia o inexistencia de arborización e invasión, estado o deterioro del mobiliario urbano y los componentes internos de los escenarios deportivos, y la inclusión o no de los elementos constitutivos de espacio público en planes para la creación, potenciación y reparación. Esta información se obtendrá en campo mediante la técnica de observación directa de los tres primeros aspectos (ambiental, invasión y mobiliario interno) y el diligenciamiento de una tabla 
que recoge de manera sistemática los datos reales que permiten la medición del déficit cualitativo de espacio público.

Tabla 3

Aspectos para la evaluación del déficit cualitativo de espacio público según su composición

\begin{tabular}{|c|c|c|c|c|c|c|c|}
\hline \multirow[t]{3}{*}{$\begin{array}{l}\text { Clasificación } \\
\text { de espacio } \\
\text { público } \\
\text { según } \\
\text { composición }\end{array}$} & \multicolumn{5}{|c|}{$\begin{array}{c}\text { Aspectos para la evaluación } \\
\text { del déficit cualitativo de espacio público }\end{array}$} & \multicolumn{2}{|c|}{$\begin{array}{c}\text { Condiciones } \\
\text { mínimas para } \\
\text { evaluación déficit } \\
\text { cualitativo } \\
\text { (CMR) }\end{array}$} \\
\hline & \multirow{2}{*}{$\begin{array}{c}1 . \\
\text { Ambiental } \\
\text { (arborización) }\end{array}$} & \multirow[t]{2}{*}{$\begin{array}{c}2 . \\
\text { Invasión }\end{array}$} & \multicolumn{2}{|c|}{$\begin{array}{c}3 . \\
\text { Mobiliario interno }\end{array}$} & \multirow{2}{*}{$\begin{array}{c}4 . \\
\text { Planes de } \\
\text { creación, } \\
\text { potenciación } \\
y \\
\text { recuperación }\end{array}$} & \multirow{2}{*}{$\begin{array}{c}\text { Espacio } \\
\text { público } \\
\text { de } \\
\text { escala } \\
\text { vecinal }\end{array}$} & \multirow{2}{*}{$\begin{array}{c}\text { Espacio } \\
\text { público } \\
\text { de } \\
\text { escala } \\
\text { zonal y } \\
\text { regiona }\end{array}$} \\
\hline & & & $\begin{array}{c}\text { En } \\
\text { escenarios } \\
\text { de escala } \\
\text { vecinal }\end{array}$ & $\begin{array}{c}\text { En } \\
\text { escenarios } \\
\text { de escala } \\
\text { zonal o } \\
\text { regional }\end{array}$ & & & \\
\hline \multirow{9}{*}{$\begin{array}{c}\text { Escenarios } \\
\text { deportivos }(A)\end{array}$} & \multirow{9}{*}{ No aplica } & Vehicular & Lámpara & Lámpara & \multirow{9}{*}{ Proyectos } & \multirow{9}{*}{11} & \multirow{9}{*}{13} \\
\hline & & $\begin{array}{l}\text { Ventas } \\
\text { informales }\end{array}$ & Caneca & Caneca & & & \\
\hline & & $\begin{array}{l}\text { Prestación } \\
\text { de } \\
\text { servicios }\end{array}$ & Señalización & Señalización & & & \\
\hline & & Basuras y & Gradería & Gradería & & & \\
\hline & & escombros & $\begin{array}{l}\text { Componente } \\
\text { Principal }^{1}\end{array}$ & $\begin{array}{l}\text { Componente } \\
\text { Principal }^{1}\end{array}$ & & & \\
\hline & & & $\begin{array}{l}\text { Campo o } \\
\text { Terreno de } \\
\text { juego }^{2} \\
\end{array}$ & $\begin{array}{l}\text { Campo o } \\
\text { Terreno de } \\
\text { juego }^{2} \\
\end{array}$ & & & \\
\hline & & & \multirow{3}{*}{$\begin{array}{l}\text { Juegos para } \\
\text { adultos }^{3}\end{array}$} & Bicicleteros & & & \\
\hline & & & & $\begin{array}{l}\text { Baños } \\
\text { públicos }\end{array}$ & & & \\
\hline & & & & $\begin{array}{l}\text { Juegos para } \\
\text { adultos }^{3}\end{array}$ & & & \\
\hline \multirow{8}{*}{$\begin{array}{c}\text { Escenarios } \\
\text { infantiles (B) }\end{array}$} & \multirow{8}{*}{ Sombra } & Vehicular & Lámpara & Lámpara & \multirow{8}{*}{ Proyectos } & \multirow{8}{*}{11} & \multirow{8}{*}{13} \\
\hline & & $\begin{array}{l}\text { Ventas } \\
\text { informales }\end{array}$ & Caneca & Caneca & & & \\
\hline & & $\begin{array}{l}\text { Prestación } \\
\text { de } \\
\text { servicios }\end{array}$ & Señalización & Señalización & & & \\
\hline & & \multirow{5}{*}{$\begin{array}{l}\text { Basuras y } \\
\text { escombros }\end{array}$} & Bancas & Bancas & & & \\
\hline & & & $\begin{array}{l}\text { Juegos o } \\
\text { Módulos } \\
\text { infantiles }\end{array}$ & $\begin{array}{l}\text { Juegos o } \\
\text { Módulos } \\
\text { infantiles }\end{array}$ & & & \\
\hline & & & Juegos para & Bicicleteros & & & \\
\hline & & & adultos $^{3}$ & $\begin{array}{l}\text { Baños } \\
\text { públicos }\end{array}$ & & & \\
\hline & & & & $\begin{array}{l}\text { Juegos para } \\
\text { adultos }^{3}\end{array}$ & & & \\
\hline \multirow{5}{*}{$\begin{array}{l}\text { Escenarios de } \\
\text { estancia (C) }\end{array}$} & \multirow{5}{*}{ Sombra } & Vehicular & Lámpara & Lámpara & \multirow{5}{*}{ Proyectos } & \multirow{5}{*}{10} & \multirow{5}{*}{12} \\
\hline & & $\begin{array}{l}\text { Ventas } \\
\text { informales }\end{array}$ & Caneca & Caneca & & & \\
\hline & & $\begin{array}{l}\text { Prestación } \\
\text { de } \\
\text { servicios }\end{array}$ & Señalización & Señalización & & & \\
\hline & & \multirow{2}{*}{$\begin{array}{l}\text { Basuras y } \\
\text { escombros }\end{array}$} & Bancas & Bancas & & & \\
\hline & & & Juegos para & Bicicleteros & & & \\
\hline
\end{tabular}




\begin{tabular}{|c|c|c|c|c|c|c|c|}
\hline & & & adultos $^{3}$ & $\begin{array}{l}\text { Baños } \\
\text { públicos }\end{array}$ & & & \\
\hline & & & & $\begin{array}{l}\text { Juegos para } \\
\text { adultos }^{3}\end{array}$ & & & \\
\hline \multirow{11}{*}{$\begin{array}{c}\text { Escenarios } \\
\text { deportivos e } \\
\text { infantiles (D) }\end{array}$} & \multirow{11}{*}{ Sombra } & Vehicular & Lámpara & Lámpara & \multirow{11}{*}{ Proyectos } & \multirow{11}{*}{14} & \multirow{11}{*}{1} \\
\hline & & $\begin{array}{l}\text { Ventas } \\
\text { informales }\end{array}$ & Caneca & Caneca & & & \\
\hline & & $\begin{array}{l}\text { Prestación } \\
\text { de } \\
\text { servicios }\end{array}$ & Señalización & Señalización & & & \\
\hline & & \multirow{8}{*}{$\begin{array}{l}\text { Basuras y } \\
\text { escombros }\end{array}$} & Bancas & Bancas & & & \\
\hline & & & $\begin{array}{l}\text { Juegos o } \\
\text { Módulos } \\
\text { infantiles }\end{array}$ & $\begin{array}{l}\text { Juegos o } \\
\text { Módulos } \\
\text { infantiles }\end{array}$ & & & \\
\hline & & & Gradería & Gradería & & & \\
\hline & & & $\begin{array}{l}\text { Componente } \\
\text { Principal }^{1}\end{array}$ & $\begin{array}{l}\text { Componente } \\
\text { Principal }^{1}\end{array}$ & & & \\
\hline & & & $\begin{array}{l}\text { Campo o } \\
\text { Terreno de } \\
\text { juego }^{2}\end{array}$ & $\begin{array}{l}\text { Campo o } \\
\text { Terreno de } \\
\text { juego }^{2}\end{array}$ & & & \\
\hline & & & \multirow{3}{*}{$\begin{array}{l}\text { Juegos para } \\
\text { adultos }^{3}\end{array}$} & Bicicleteros & & & \\
\hline & & & & $\begin{array}{l}\text { Baños } \\
\text { públicos }\end{array}$ & & & \\
\hline & & & & $\begin{array}{l}\text { Juegos para } \\
\text { adultos }^{3}\end{array}$ & & & \\
\hline \multirow{8}{*}{$\begin{array}{c}\text { Escenarios de } \\
\text { estancia e } \\
\text { infantiles (E) }\end{array}$} & \multirow{8}{*}{ Sombra } & \multirow[t]{2}{*}{ Vehicular } & Lámpara & Lámpara & \multirow{8}{*}{ Proyectos } & \multirow{8}{*}{11} & \multirow{8}{*}{13} \\
\hline & & & Caneca & Caneca & & & \\
\hline & & Ventas & Señalización & Señalización & & & \\
\hline & & informales & Bancas & Bancas & & & \\
\hline & & $\begin{array}{l}\text { Prestación } \\
\text { de } \\
\text { servicios }\end{array}$ & $\begin{array}{l}\text { Juegos o } \\
\text { Módulos } \\
\text { infantiles }\end{array}$ & $\begin{array}{l}\text { Juegos o } \\
\text { Módulos } \\
\text { infantiles }\end{array}$ & & & \\
\hline & & & \multirow{3}{*}{$\begin{array}{l}\text { Juegos para } \\
\text { adultos }^{3}\end{array}$} & Bicicleteros & & & \\
\hline & & \multirow[t]{2}{*}{$\begin{array}{l}\text { Basuras y } \\
\text { escombros }\end{array}$} & & $\begin{array}{l}\text { Baños } \\
\text { públicos }\end{array}$ & & & \\
\hline & & & & $\begin{array}{l}\text { Juegos para } \\
\text { adultos }^{3}\end{array}$ & & & \\
\hline \multirow{10}{*}{$\begin{array}{c}\text { Escenarios de } \\
\text { estancia y } \\
\text { deportivos (F) }\end{array}$} & \multirow{10}{*}{ Sombra } & Vehicular & Lámpara & Lámpara & \multirow{10}{*}{ Proyectos } & \multirow{10}{*}{13} & \multirow{10}{*}{15} \\
\hline & & $\begin{array}{l}\text { Ventas } \\
\text { informales }\end{array}$ & Caneca & Caneca & & & \\
\hline & & $\begin{array}{l}\text { Prestación } \\
\text { de } \\
\text { servicios }\end{array}$ & Señalización & Señalización & & & \\
\hline & & Basuras y & Bancas & Bancas & & & \\
\hline & & escombros & Gradería & Gradería & & & \\
\hline & & & $\begin{array}{l}\text { Componente } \\
\text { Principal }^{1}\end{array}$ & $\begin{array}{l}\text { Componente } \\
\text { Principal }^{1}\end{array}$ & & & \\
\hline & & & $\begin{array}{l}\text { Campo o } \\
\text { Terreno de } \\
\text { jueg }^{2}\end{array}$ & $\begin{array}{l}\text { Campo o } \\
\text { Terreno de } \\
\text { juego }^{2}\end{array}$ & & & \\
\hline & & & Juegos para & Bicicleteros & & & \\
\hline & & & adultos $^{3}$ & $\begin{array}{l}\text { Baños } \\
\text { públicos }\end{array}$ & & & \\
\hline & & & & $\begin{array}{l}\text { Juegos para } \\
\text { adultos }^{3}\end{array}$ & & & \\
\hline & & Vehicular & Lámpara & Lámpara & & & \\
\hline $\begin{array}{c}\text { Escenarios de } \\
\text { estancia y }\end{array}$ & Sombra & $\begin{array}{l}\text { Ventas } \\
\text { informales }\end{array}$ & Caneca & Caneca & Proyectos & 14 & 16 \\
\hline deportivos (G) & & $\begin{array}{l}\text { Prestación } \\
\text { de }\end{array}$ & Señalización & Señalización & & & \\
\hline
\end{tabular}




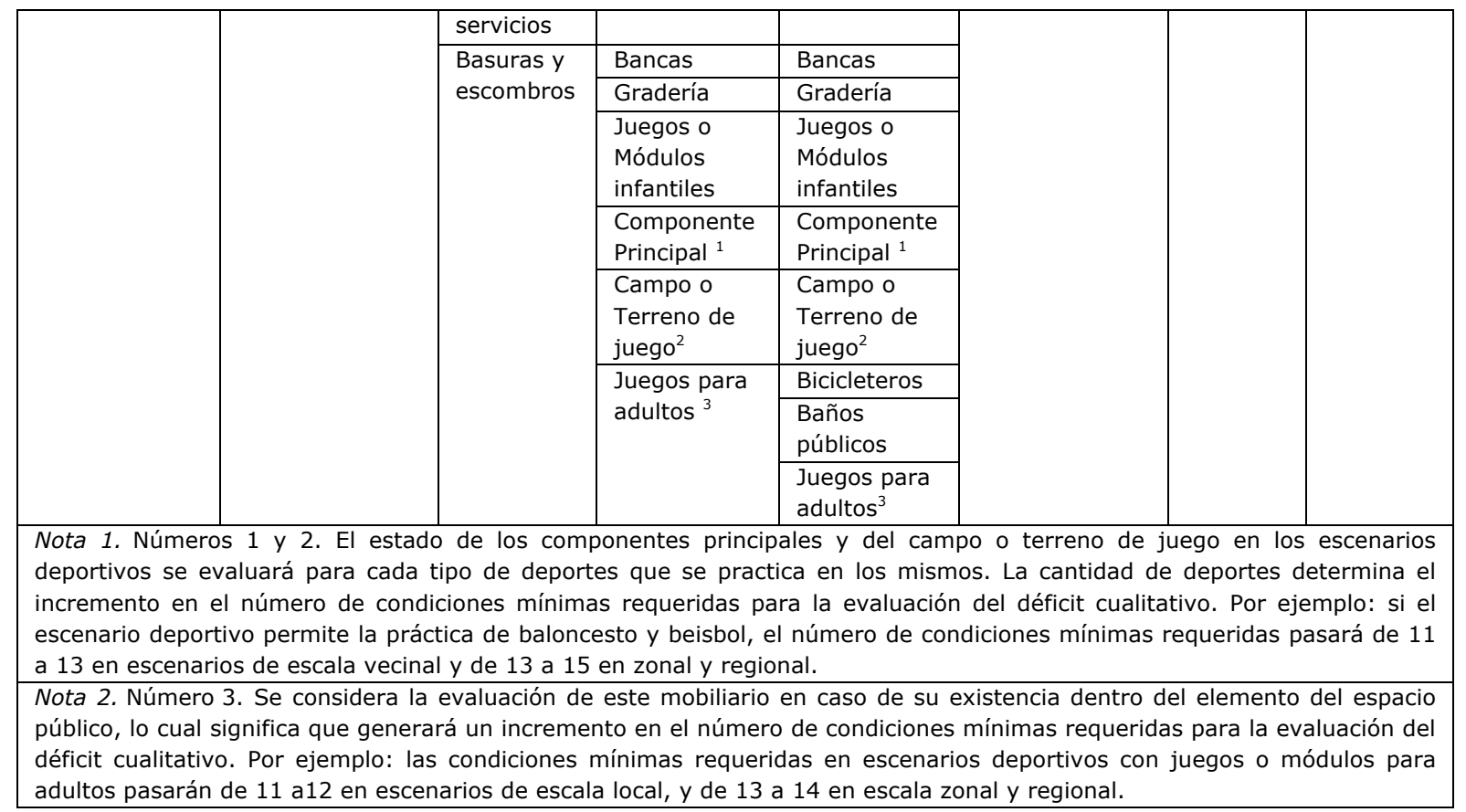

Fuente: Elaboración propia ajustada de Jiménez (2009).En síntesis, los aspectos para la evaluación del déficit cualitativo de espacio público diverso se complementarán de acuerdo con las posibles combinaciones de las tres composiciones individuales, lo que aumentará las condiciones mínimas requeridas (CMR) en su cálculo. Por ejemplo, un elemento de espacio público compuesto por escenarios infantiles debería evaluarse bajo $11 \mathrm{CMR}$, lo que difiere de la composición de un escenario deportivo e infantil al tener en cuenta 14 , ya que se incluyen las graderías, el campo o terreno de juego donde se practica el deporte y el componente deportivo principal.

La estimación del déficit cualitativo de espacio público que se plantea, es aplicable a cualquier entorno urbano, dado que toma como base una clasificación del espacio público según la composición y función que presta a la sociedad, la cual integra en sus tres categorías (escenarios infantiles, deportivos y de estancia) a la gran mayoría de tipologías de espacios públicos articuladores, de intercambio y encuentro ciudadano, presentes en las ciudades, como los parques, las rondas hídricas, las canchas deportivas, las plazoletas, entre otras. Asimismo, tiene en cuenta la clasificación según la escala o área de influencia (vecinal, zonal y regional). Tanto la función como la escala son aspectos que definen las condiciones mínimas requeridas para evaluar el estado físico de un elemento del espacio público.

Como caso de estudio para demostrar el funcionamiento de la metodología que permite medir el déficit cualitativo de espacio público se escogió la ciudad de Montería, capital del departamento de Córdoba en Colombia, cuyo valor per cápita es inferior a $4 \mathrm{~m}^{2} /$ habitante, por debajo de los $15 \mathrm{~m}^{2} /$ habitante exigidos. Su emplazamiento es sobre la planicie aluvial del río Sinú, elemento natural 
que se ha convertido en el estructurador del espacio regional de Córdoba y municipal de sur a norte.

Según estimaciones del Departamento Administrativo Nacional de Estadística (DANE), para el año 2015 la población urbana de Montería era de 330.313 habitantes y está conformada por 207 barrios, los cuales por presentar características similares en cuanto a niveles socioeconómicos, infraestructuras viales, de comercio y servicios, son agrupados en su conjunto a través de nueve comunas, de las que la parte occidental participa con dos, constituyéndose por 44 barrios en condiciones socioeconómicas bajas y 51 elementos del espacio público. Se encuentran aquí escenarios de estancia, infantiles, deportivos en forma individual o combinados, por ejemplo, deportivo e infantil, estancia y deportivo, entre otras combinaciones. En su mayoría, son parques o escenarios deportivos de escala vecinal y zonal, que satisfacen las necesidades de recreación y deporte de la población.

La implementación de la metodología propuesta para la medición del déficit cualitativo de espacio público requiere de la información actualizada acerca la existencia y condiciones físico-espaciales de los diferentes elementos que lo constituyen, la cual es de dominio y competencia del Estado, siendo su deber garantizar el acceso al mismo. Es así que las Secretarías de Planeación y de Infraestructura municipal están llamadas a medir tal valoración cualitativa como base para su intervención. Del mismo modo, las empresas privadas prestadoras de servicios públicos y del mantenimiento del mobiliario urbano demandan de esta valoración cualitativa para responder de forma óptima a su funcionamiento, lo que incide en la calidad de vida de los ciudadanos, quienes dependiendo de las condiciones cualitativas del espacio público, podrán o no acceder al mismo para disfrutar, usar y gozar de su funcionamiento.

\section{Resultados y discusión}

Instrumento de recolección de información para el cálculo del déficit cualitativo de espacio público. La información primaria obtenida a través de la inspección ocular se registra a través de un instrumento ${ }^{4}$ diseñado para identificar de manera individual los elementos del espacio público existente, clasificarlo según su composición, función y escala, y conocer las condiciones que generan o no déficit cualitativo, siendo valoradas de uno (1) y cero (0), respectivamente, lo que permitirá compararlas con las condiciones mínimas requeridas que fueron determinadas en la Tabla 3.

A continuación se describe el contenido de dicho instrumento, tomando como ejemplos nueve elementos de espacio público de la ciudad de Montería que evidencian su diversidad funcional y cuyos datos fueron obtenidos en el mes de octubre de 2015 (Tablas 4 a 7).

\footnotetext{
${ }^{4}$ Instrumento que contiene los cuatro aspectos para evaluar el déficit cualitativo de espacio público y que para efectos de este artículo se ha dividido en cuatro tablas $(4,5,6$ y 7$)$.
} 
Información de referencia. Se parte de la identificación del elemento de espacio público usando una codificación para ser manejado en el contexto de las bases de datos geográficas, la cual puede darse por un reconocimiento previo que se obtiene de fuentes secundarias o primaria in situ; continuándose con la asignación de su nombre, el que corresponderá al reconocimiento que hacen sus habitantes y la administración municipal; así como con la categoría de clasificación según su composición y escala o influencia teniendo en cuenta los criterios previamente establecidos en las Tablas 1 y 2 (Tabla 4).

Tabla 4

Información de referencia

\begin{tabular}{|c|c|c|c|}
\hline Código & Nombre & $\begin{array}{c}\text { Categoría de } \\
\text { clasificación según su } \\
\text { composición }\end{array}$ & $\begin{array}{c}\text { Categoría de } \\
\text { clasificación según la } \\
\text { escala o influencia }\end{array}$ \\
\hline $\mathrm{C} 1-01$ & $\begin{array}{c}\text { Parque } \\
\text { Rancho } \\
\text { Grande \#3 }\end{array}$ & $\begin{array}{l}\text { Escenario de estancia, } \\
\text { infantil y deportivo }\end{array}$ & Vecinal \\
\hline C1-09 & $\begin{array}{l}\text { Cancha } \\
\text { Holanda }\end{array}$ & Escenario deportivo & Zonal \\
\hline C1-14 & $\begin{array}{l}\text { Parque La } \\
\text { Rivera \#4 }\end{array}$ & Escenario de estancia & Vecinal \\
\hline$C 2-03$ & $\begin{array}{c}\text { Parque El } \\
\text { Amparo \#2 }\end{array}$ & Escenario infantil & Zonal \\
\hline $\mathrm{C} 2-13$ & $\begin{array}{l}\text { Parque El } \\
\text { Tambo }\end{array}$ & $\begin{array}{c}\text { Escenario de estancia y } \\
\text { deportivo }\end{array}$ & Vecinal \\
\hline $\mathrm{C} 2-17$ & $\begin{array}{l}\text { Parque } \\
\text { Alboraya } \\
\text { Nuevo }\end{array}$ & $\begin{array}{l}\text { Escenario de estancia e } \\
\text { infantil }\end{array}$ & Vecinal \\
\hline C5-01 & $\begin{array}{l}\text { Ronda del } \\
\text { Sinú }\end{array}$ & $\begin{array}{l}\text { Escenario de estancia e } \\
\text { infantil }\end{array}$ & Regional \\
\hline C8-02 & $\begin{array}{l}\text { Parque Los } \\
\text { Ángeles \#2 }\end{array}$ & $\begin{array}{c}\text { Escenario deportivo e } \\
\text { infantil }\end{array}$ & Vecinal \\
\hline C8-03 & $\begin{array}{l}\text { Parque La } \\
\text { Floresta \#2 }\end{array}$ & $\begin{array}{l}\text { Escenario de estancia e } \\
\text { infantil }\end{array}$ & Vecinal \\
\hline
\end{tabular}

Fuente: Elaboración propia.

La clasificación de los elementos de espacio público según dicha composición y escala determinan el número de condiciones mínimas requeridas para evaluar el déficit cualitativo del espacio público, que para el caso de los escenarios deportivos e infantiles cada uno, están entre 11 y 13; y de los escenarios de estancia entre 10 y 12 (Tabla 3). Estas aumentarán en la medida que exista diversidad. 
Aspectos ambientales (arborización) e invasión. Una vez que ha sido obtenida la información de referencia, se procede al diligenciamiento de los aspectos ambiental e invasión. El primero, reconoce la existencia de la vegetación, dando respuesta con un "Sí", en el caso de los escenarios de estancia e infantiles, o un "No", solo en escenarios deportivos. Se parte de la idea de que funcionalmente la población puede realizar actividades de recreación pasiva siempre que exista sombra (Tabla 5).

El segundo, la invasión, refleja la función pública y el carácter jurídico del dominio público de estos espacios, además de las afectaciones que pueden originarse por tales condiciones hasta el punto de limitar su uso.

Tabla 5

Aspectos para la evaluación del déficit cualitativo de espacio público (EP) articulador, de intercambio y encuentro ciudadano. Parte 1 y 2

\begin{tabular}{|c|c|c|c|c|c|c|c|c|c|c|c|}
\hline \multirow[b]{3}{*}{$\begin{array}{c}\text { Código del } \\
\text { espacio } \\
\text { público } \\
\text { evaluado }\end{array}$} & \multirow{2}{*}{\multicolumn{3}{|c|}{$\begin{array}{c}\begin{array}{c}1 . \\
\text { Ambiental } \\
\text { (arborización) }\end{array} \\
\begin{array}{c}1.1 . \\
\text { Sombra }\end{array}\end{array}$}} & \multicolumn{8}{|c|}{$\begin{array}{c}2 . \\
\text { Invasión }\end{array}$} \\
\hline & & & & \multicolumn{2}{|c|}{$\begin{array}{c}2.1 . \\
\text { Vehicular }\end{array}$} & \multicolumn{2}{|c|}{$\begin{array}{c}2.2 . \\
\text { Ventas } \\
\text { informales }\end{array}$} & \multicolumn{2}{|c|}{$\begin{array}{c}2.3 . \\
\text { Prestación } \\
\text { de servicios }\end{array}$} & \multicolumn{2}{|c|}{$\begin{array}{c}2.4 . \\
\text { Basura o } \\
\text { escombros }\end{array}$} \\
\hline & 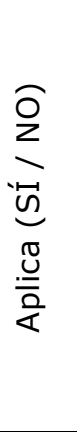 & 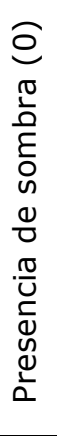 & 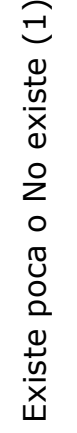 & 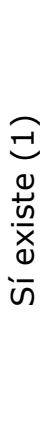 & $\begin{array}{l}0 \\
0 \\
\stackrel{0}{y} \\
\frac{\omega}{x} \\
0 \\
0 \\
z\end{array}$ & 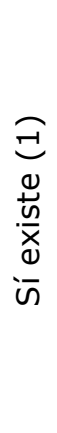 & $\begin{array}{l}0 \\
0 \\
0 \\
\stackrel{y}{0} \\
\frac{0}{x} \\
0 \\
0 \\
z\end{array}$ & 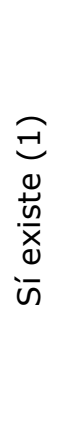 & $\begin{array}{l}0 \\
0 \\
0 \\
\stackrel{0}{0} \\
\frac{0}{x} \\
0 \\
0 \\
z\end{array}$ & 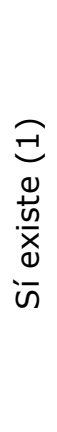 & 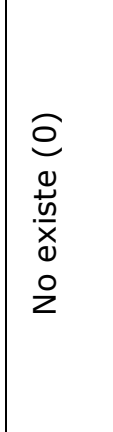 \\
\hline C1-01 & Sí & \multicolumn{2}{|c|}{0} & & 1 & \multicolumn{2}{|r|}{$\frac{1}{1}$} & \multicolumn{2}{|c|}{0} & \multicolumn{2}{|c|}{$\frac{1}{1}$} \\
\hline C1-09 & No & \multicolumn{2}{|c|}{-----} & & 1 & \multicolumn{2}{|r|}{1} & \multicolumn{2}{|c|}{1} & \multicolumn{2}{|c|}{1} \\
\hline C1-14 & Sí & \multicolumn{2}{|c|}{0} & & 1 & \multicolumn{2}{|c|}{0} & \multicolumn{2}{|c|}{0} & \multicolumn{2}{|c|}{0} \\
\hline C2-03 & Sí & \multicolumn{2}{|c|}{1} & & 0 & \multicolumn{2}{|c|}{0} & \multicolumn{2}{|c|}{0} & \multicolumn{2}{|c|}{1} \\
\hline C2-13 & Sí & \multicolumn{2}{|c|}{0} & & 1 & \multicolumn{2}{|c|}{0} & \multicolumn{2}{|c|}{0} & \multicolumn{2}{|c|}{1} \\
\hline C2-17 & Sí & \multicolumn{2}{|c|}{0} & & 0 & \multicolumn{2}{|c|}{0} & \multicolumn{2}{|c|}{0} & \multicolumn{2}{|c|}{0} \\
\hline C5-01 & Sí & \multicolumn{2}{|c|}{0} & & 1 & \multicolumn{2}{|c|}{0} & \multicolumn{2}{|c|}{0} & \multicolumn{2}{|c|}{1} \\
\hline C8-02 & Sí & \multicolumn{2}{|c|}{0} & & 0 & \multicolumn{2}{|c|}{0} & & 0 & & 0 \\
\hline C8-03 & SI & & 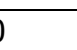 & & 0 & & 0 & & 0 & & 0 \\
\hline
\end{tabular}

Fuente: Elaboración propia.

La existencia de los diferentes tipos de invasión en el espacio público existente se registra en el instrumento con un valor de uno (1), que indica una condición generadora de déficit cualitativo y cero $(0)$ en caso contrario. 
Mobiliario urbano. Para dar continuidad al registro de la información en campo mediante el instrumento se requiere de la valoración del estado cualitativo del mobiliario urbano compuesto por bancas, luminarias peatonales, canecas, señalización, módulos infantiles, módulos y juegos para jóvenes y adultos, bicicleteros y baños públicos. Los dos últimos resultan esenciales en los escenarios deportivos a escalas zonal y regional.

Particularmente, en los escenarios deportivos se valoran como mobiliario o componente interno las gradas, campo o terreno de juego y el componente interno según cada deporte, constituido este último por el conjunto de elementos esenciales que caracterizan a cada escenario para la práctica del deporte, por ejemplo, los arcos en fútbol, microfútbol y minifútbol; las cestas en baloncesto, las mallas en voleibol y tenis; las almohadillas en softbol y béisbol, entre otros.

Por su parte, el mobiliario urbano es valorado según las categorías "buen estado o sin deterioro" con un valor de cero (0); "mal estado o deteriorado"; y "no tiene" con un valor uno (1). Este resulta importante al evaluar las condiciones generadoras de déficit, debido a que demuestra qué tanto aportan estos elementos complementarios al adecuado funcionamiento del espacio público (Tabla 6). 
Tabla 6

Aspectos para la evaluación del déficit cualitativo de espacio público (EP) articulador, de intercambio y encuentro ciudadano. Parte 3 (3.1)

\begin{tabular}{|c|c|c|c|c|c|c|c|c|c|c|c|c|c|c|c|c|c|c|c|c|c|c|c|c|c|c|c|c|c|}
\hline \multirow{4}{*}{ 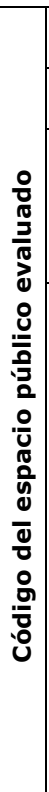 } & \multicolumn{29}{|c|}{$\begin{array}{c}3 . \\
\text { Mobiliario o componente interno }\end{array}$} \\
\hline & \multicolumn{29}{|c|}{$\begin{array}{l}3.1 . \\
\text { Mobiliario o componente interno en escena }\end{array}$} \\
\hline & \multicolumn{3}{|c|}{$\begin{array}{l}\text { 3.1.1. } \\
\text { Bancas }\end{array}$} & \multicolumn{4}{|c|}{$\begin{array}{c}3.1 .2 . \\
\text { Luminaria } \\
\text { peatonal }\end{array}$} & \multicolumn{4}{|c|}{$\begin{array}{l}\text { 3.1.3. } \\
\text { Caneca }\end{array}$} & \multicolumn{4}{|c|}{$\begin{array}{l}\text { 3.1.4. } \\
\text { Señalización }\end{array}$} & \multicolumn{3}{|c|}{$\begin{array}{l}\text { 3.1.5. } \\
\text { Módulo } \\
\text { infantil }\end{array}$} & \multicolumn{3}{|c|}{$\begin{array}{c}\text { 3.1.6. } \\
\text { Módulo y } \\
\text { juegos } \\
\text { para } \\
\text { jóvenes y } \\
\text { adultos } \\
\end{array}$} & \multicolumn{4}{|c|}{$\begin{array}{c}\text { 3.1.7. } \\
\text { Bicicletero }\end{array}$} & \multicolumn{4}{|c|}{$\begin{array}{l}\text { 3.1.8. } \\
\text { Baño público }\end{array}$} \\
\hline & 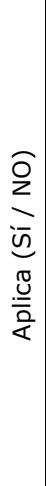 & 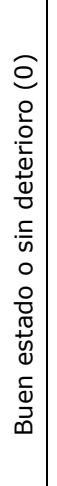 & 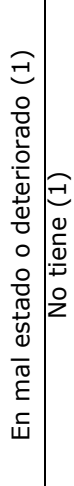 & 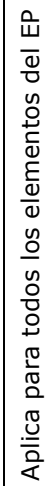 & 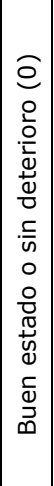 & 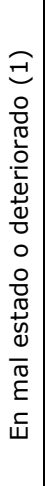 & 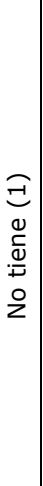 & 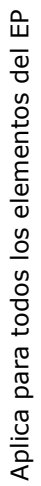 & 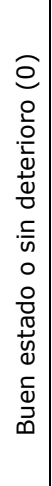 & 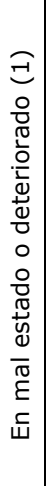 & 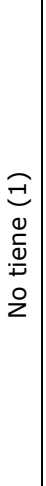 & 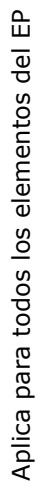 & 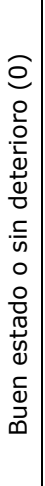 & 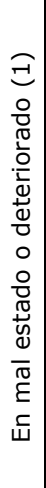 & 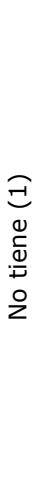 & 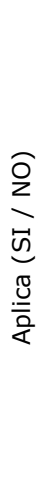 & 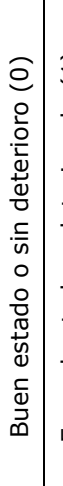 & 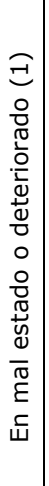 & 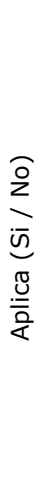 & 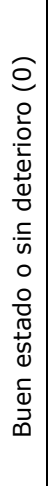 & 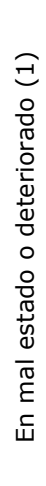 & 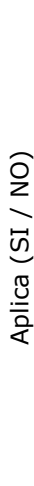 & 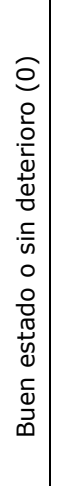 & 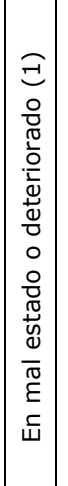 & 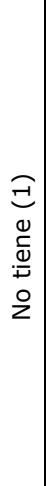 & 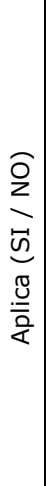 & 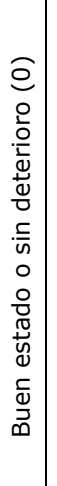 & 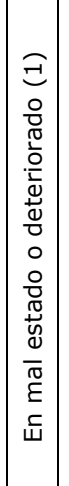 & 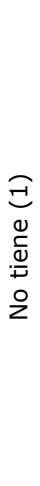 \\
\hline $\begin{array}{l}- \\
0 \\
1 \\
\dot{u}\end{array}$ & $\bar{n}$ & & 1 & in & & 0 & & in & & 1 & & $\bar{n}$ & & 1 & & $\bar{n}$ & 1 & & $\bar{n}$ & 1 & & 우 & & $-\cdots$ & & ò & & ---- & \\
\hline $\begin{array}{l}0 \\
0 \\
1 \\
ن \\
ن\end{array}$ & ㅇ & & $-\cdots$ & in & & 0 & & in & & 1 & & $\bar{n}$ & & 1 & & 울 & --- & & 울 & --- & & $\bar{n}$ & & 1 & & $\bar{\omega}$ & & 1 & \\
\hline $\begin{array}{c}-1 \\
\stackrel{1}{u}\end{array}$ & $\bar{n}$ & & 0 & in & & 1 & & in & & 1 & & $\bar{n}$ & & 1 & & ㅇ & --- & & $\bar{n}$ & 1 & & 우 & & $-\cdots$ & & ò & & --- & \\
\hline $\begin{array}{l}\text { On } \\
\text { ஸे } \\
\text { Ũ }\end{array}$ & $\bar{n}$ & & 1 & in & & 0 & & $\bar{n}$ & & 1 & & $\bar{n}$ & & 1 & & $\bar{n}$ & 1 & & 을 & --- & & $\bar{n}$ & & 1 & & $\bar{n}$ & & 1 & \\
\hline 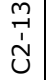 & $\bar{n}$ & & 1 & in & & 1 & & $\bar{n}$ & & 1 & & $\bar{n}$ & & 1 & & z & --- & & $\bar{n}$ & 1 & & $\stackrel{\circ}{2}$ & & ---- & & ? & & ---- & \\
\hline ثे & $\bar{n}$ & & 0 & $\overline{i n}$ & & 0 & & $\bar{n}$ & & 0 & & $\bar{n}$ & & 0 & & $\bar{n}$ & 0 & & $\bar{n}$ & 0 & & 울 & & ---- & & 20 & & --- & \\
\hline $\begin{array}{l}0 \\
0 \\
\text { ஸे }\end{array}$ & $\bar{n}$ & & 0 & $\overline{i n}$ & & 0 & & $\bar{n}$ & & 0 & & $\bar{n}$ & & 0 & & $\bar{n}$ & 0 & & $\bar{n}$ & 1 & & $\bar{n}$ & & 0 & & $\bar{n}$ & & 0 & \\
\hline $\begin{array}{l}0 \\
0 \\
1 \\
0 \\
0\end{array}$ & $\bar{n}$ & & 1 & $\bar{c}$ & & 1 & & $\bar{n}$ & & 1 & & $\bar{n}$ & & 1 & & $\bar{n}$ & 1 & & $z$ & -- & & 2 & & --.- & & z & & ---- & \\
\hline $\begin{array}{l}\text { mo } \\
0 \\
1 \\
0 \\
0\end{array}$ & $\bar{n}$ & & 0 & $\bar{n}$ & & 1 & & $\bar{n}$ & & 1 & & $\bar{n}$ & & 1 & & $\bar{n}$ & 0 & & $z$ & --- & & $z$ & & $-\cdots$ & & $z$ & & --- & \\
\hline
\end{tabular}

Fuente: Elaboración propia. 


\section{Tabla 7}

Aspectos para la evaluación del déficit cualitativo de espacio público (EP) articulador, de intercambio y encuentro ciudadano. Parte 3 (3.2 y 4)

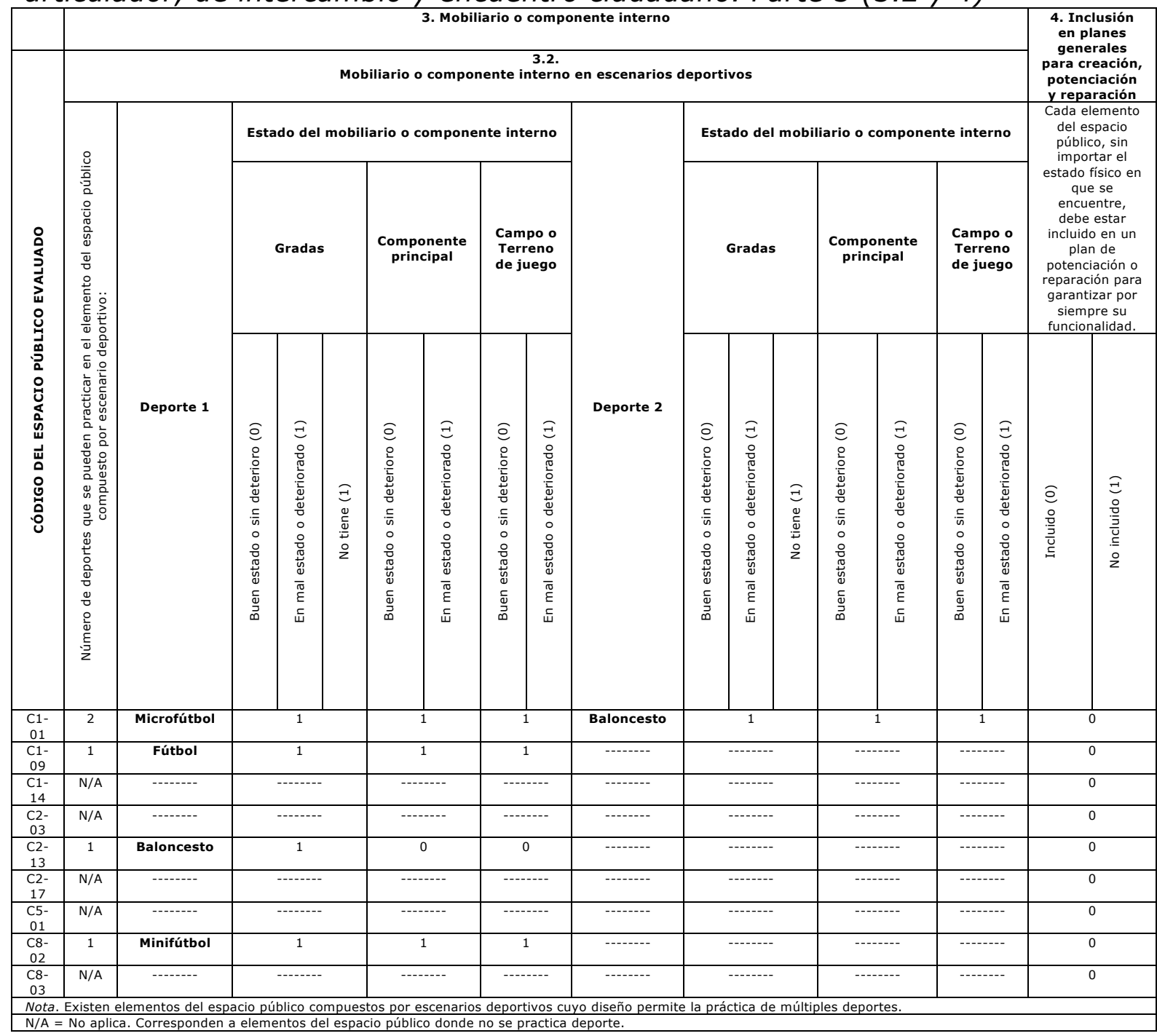

Fuente: Elaboración propia.

A partir del diligenciamiento de la información requerida para el cálculo del déficit cualitativo en la tabla se procederá a aplicar la fórmula del mismo (MCGD/CMR) x 100, donde, CMR son las condiciones mínimas requeridas para que no exista déficit cualitativo en los elementos del espacio público (Tabla 3 ), en tanto que MCGD se refiere a las malas condiciones generadores de déficit cualitativo, representadas a través del número (1) en las Tablas 5, 6 y 7.

Como resultado del déficit cualitativo se obtienen valores que oscilan entre el $0,00 \%$ y el $100,00 \%$, donde cero $(0,00)$ evidencia excelente estado cualitativo de los elementos de espacio público, debido a la ausencia de alguna condición 
generadora de déficit y $100(100,00)$ el mal estado de los mismos por la total presencia de dichas condiciones. En esta propuesta metodológica para la medición del déficit cualitativo del espacio público se asume la valoración cualitativa porcentual a partir de los rangos contenidos en la Tabla 8.

Tabla 8

Rangos porcentuales de valoración cualitativa del déficit de espacio público

\begin{tabular}{|c|l|}
\hline Rangos & \multicolumn{1}{|c|}{ Categoría } \\
\hline $0,00 \%$ & Déficit nulo \\
\hline $0,01 \%-15,00 \%$ & Muy bajo déficit \\
\hline $15,01 \%-30,00 \%$ & Bajo déficit \\
\hline $30,01 \%-60,00 \%$ & Alto déficit \\
\hline $61,01 \%-99,99 \%$ & Muy alto déficit \\
\hline $100,00 \%$ & Déficit total \\
\hline
\end{tabular}

Fuente: Elaboración propia.

Es de considerar que el mal estado de los componentes internos principales de cada escenario deportivo (campo o terreno de juego, arcos, cestas, mallas, entre otros), infantil (módulos infantiles) y de estancia (bancas y sombras) permite valorarlo como muy alto déficit, debido a que impide el óptimo funcionamiento de estos. Es así que se puede obtener un porcentaje de déficit cualitativo con valores cercanos a $0,00 \%$ en el caso de que un escenario infantil tenga todo el mobiliario o componente interno en buenas condiciones, sin embargo, los columpios o módulos infantiles estén deteriorados; también puede ocurrir en una cancha de fútbol cuyo campo o terreno de juego se observe en buen estado, pero los arcos no existen o se encuentran en mal estado; del mismo modo, que un escenario de estancia bien dotado y que solo carezca de sombra, obtendrá una valoración negativa.

Particularmente, en cada categoría de déficit cualitativo existe un número de condiciones generadores del mismo, las que dependen del tipo de escenario y sus combinaciones, así como de la escala o influencia, como se observa en las Tablas $9,10,11,12,13$ y 14 . 
Tabla 9

Número de condiciones generadoras de déficit cualitativo en el nivel Nulo $(0,00 \%)$

\begin{tabular}{|c|c|c|c|c|c|c|c|}
\hline $\begin{array}{c}\text { Área de } \\
\text { influencia } \\
\text { o escala }\end{array}$ & $\begin{array}{c}\text { Escenario } \\
\text { deportivo }\end{array}$ & $\begin{array}{c}\text { Escenario } \\
\text { de } \\
\text { estancia }\end{array}$ & $\begin{array}{c}\text { Escenario } \\
\text { infantil }\end{array}$ & $\begin{array}{c}\text { Escenario } \\
\text { deportivo } \\
\text { e infantil }\end{array}$ & $\begin{array}{c}\text { Escenario } \\
\text { de } \\
\text { estancia e } \\
\text { infantil }\end{array}$ & $\begin{array}{c}\text { Escenario } \\
\text { de } \\
\text { estancia y } \\
\text { deportivo }\end{array}$ & $\begin{array}{c}\text { Escenario } \\
\text { de } \\
\text { estancia, } \\
\text { infantil y } \\
\text { deportivo }\end{array}$ \\
\hline Vecinal & 0 & 0 & 0 & 0 & 0 & 0 & 0 \\
\hline $\begin{array}{c}\text { Zonal }- \\
\text { Regional }\end{array}$ & 0 & 0 & 0 & 0 & 0 & 0 & 0 \\
\hline
\end{tabular}

Fuente: Elaboración propia.

Tabla 10

Número de condiciones generadoras de déficit cualitativo en el nivel Muy bajo $(0,01-15,00 \%)$

\begin{tabular}{|c|c|c|c|c|c|c|c|}
\hline $\begin{array}{c}\text { Área de } \\
\text { influencia } \\
\text { o escala }\end{array}$ & $\begin{array}{c}\text { Escenario } \\
\text { deportivo }\end{array}$ & $\begin{array}{c}\text { Escenario } \\
\text { de } \\
\text { estancia }\end{array}$ & $\begin{array}{c}\text { Escenario } \\
\text { infantil }\end{array}$ & $\begin{array}{c}\text { Escenario } \\
\text { deportivo } \\
\text { e infantil }\end{array}$ & $\begin{array}{c}\text { Escenario } \\
\text { de } \\
\text { estancia e } \\
\text { infantil }\end{array}$ & $\begin{array}{c}\text { Escenario } \\
\text { de } \\
\text { estancia y } \\
\text { deportivo }\end{array}$ & $\begin{array}{c}\text { Escenario } \\
\text { de } \\
\text { estancia, } \\
\text { infantil y } \\
\text { deportivo }\end{array}$ \\
\hline Vecinal & 1 & 1 & 1 & 1 a 2 & 1 & 1 & 1 \\
\hline $\begin{array}{c}\text { Zonal - } \\
\text { Regional }\end{array}$ & 1 & 1 & 1 & 1 a 2 & 1 & 1 a 2 & 1 a 2 \\
\hline
\end{tabular}

Fuente: Elaboración propia.

Tabla 11

Número de condiciones generadoras de déficit cualitativo en el nivel Bajo (15,01 - 30,00\%)

\begin{tabular}{|c|c|c|c|c|c|c|c|}
\hline $\begin{array}{c}\text { Área de } \\
\text { influencia } \\
\text { o escala }\end{array}$ & $\begin{array}{c}\text { Escenario } \\
\text { deportivo }\end{array}$ & $\begin{array}{c}\text { Escenario } \\
\text { de } \\
\text { estancia }\end{array}$ & $\begin{array}{c}\text { Escenario } \\
\text { infantil }\end{array}$ & $\begin{array}{c}\text { Escenario } \\
\text { deportivo } \\
\text { e infantil }\end{array}$ & $\begin{array}{c}\text { Escenario } \\
\text { de } \\
\text { estancia e } \\
\text { infantil }\end{array}$ & $\begin{array}{c}\text { Escenario } \\
\text { de } \\
\text { estancia y } \\
\text { deportivo }\end{array}$ & $\begin{array}{c}\text { Escenario } \\
\text { de } \\
\text { estancia, } \\
\text { infantil y } \\
\text { deportivo }\end{array}$ \\
\hline Vecinal & 2 a 3 & 2 a 3 & 2 a 3 & 3 a 4 & 2 a 3 & 2 a 3 & 3 a 4 \\
\hline $\begin{array}{c}\text { Zonal - } \\
\text { Regional }\end{array}$ & 2 a 3 & 2 a 3 & 2 a 3 & 3 a 4 & 2 a 3 & 3 a 4 & 3 a 4 \\
\hline
\end{tabular}

Fuente: Elaboración propia.

Tabla 12

Número de condiciones generadoras de déficit cualitativo en el nivel Alto $(30,01-60,00 \%)$

\begin{tabular}{|c|c|c|c|c|c|c|c|}
\hline $\begin{array}{c}\text { Área de } \\
\text { influencia } \\
\text { o escala }\end{array}$ & $\begin{array}{c}\text { Escenario } \\
\text { deportivo }\end{array}$ & $\begin{array}{c}\text { Escenario } \\
\text { de } \\
\text { estancia }\end{array}$ & $\begin{array}{c}\text { Escenario } \\
\text { infantil }\end{array}$ & $\begin{array}{c}\text { Escenario } \\
\text { deportivo } \\
\text { e infantil }\end{array}$ & $\begin{array}{c}\text { Escenario } \\
\text { de } \\
\text { estancia e } \\
\text { infantil }\end{array}$ & $\begin{array}{c}\text { Escenario } \\
\text { de } \\
\text { estancia y } \\
\text { deportivo }\end{array}$ & $\begin{array}{c}\text { Escenario } \\
\text { de } \\
\text { estancia, } \\
\text { infantil y } \\
\text { deportivo }\end{array}$ \\
\hline Vecinal & 4 a 6 & 4 a 6 & 4 a 6 & 5 a 8 & 4 a 6 & 4 a 7 & 5 a 8 \\
\hline $\begin{array}{c}\text { Zonal - } \\
\text { Regional }\end{array}$ & 4 a 7 & 4 a 7 & 4 a 7 & 5 a 9 & 4 a 7 & 5 a 9 & 5 a 9 \\
\hline
\end{tabular}

Fuente: Elaboración propia.

Tabla 13

Número de condiciones generadoras de déficit cualitativo en el nivel Muy Alto $(61,01-99,99 \%)$

\begin{tabular}{|c|c|c|c|c|c|c|c|}
\hline $\begin{array}{c}\text { Área de } \\
\text { influencia } \\
\text { o escala }\end{array}$ & $\begin{array}{l}\text { Escenario } \\
\text { deportivo }\end{array}$ & $\begin{array}{c}\text { Escenario } \\
\text { de } \\
\text { estancia }\end{array}$ & $\begin{array}{c}\text { Escenario } \\
\text { infantil }\end{array}$ & $\begin{array}{l}\text { Escenario } \\
\text { deportivo } \\
\text { e infantil }\end{array}$ & $\begin{array}{c}\text { Escenario } \\
\text { de } \\
\text { estancia } \\
\text { e infantil }\end{array}$ & $\begin{array}{c}\text { Escenario } \\
\text { de } \\
\text { estancia } \\
y \\
\text { deportivo }\end{array}$ & $\begin{array}{c}\text { Escenario } \\
\text { de } \\
\text { estancia, } \\
\text { infantil y } \\
\text { deportivo }\end{array}$ \\
\hline Vecinal & 7 a 10 & 7 a 9 & 7 a 10 & 9 a 13 & 7 a 10 & 8 a 12 & 9 a 13 \\
\hline $\begin{array}{c}\text { Zonal - } \\
\text { Regional }\end{array}$ & 8 a 12 & 8 a 11 & 8 a 12 & 10 a 15 & 8 a 12 & 10 a 14 & 10 a 15 \\
\hline
\end{tabular}

Fuente: Elaboración propia. 
Tabla 14

Número de condiciones generadoras de déficit cualitativo en el nivel Total $(100,00 \%)$

\begin{tabular}{|c|c|c|c|c|c|c|c|}
\hline $\begin{array}{c}\text { Área de } \\
\text { influencia } \\
\text { o escala }\end{array}$ & $\begin{array}{c}\text { Escenario } \\
\text { deportivo }\end{array}$ & $\begin{array}{c}\text { Escenario } \\
\text { de } \\
\text { estancia }\end{array}$ & $\begin{array}{c}\text { Escenario } \\
\text { infantil }\end{array}$ & $\begin{array}{c}\text { Escenario } \\
\text { deportivo } \\
\text { e infantil }\end{array}$ & $\begin{array}{c}\text { Escenario } \\
\text { de } \\
\text { estancia } \\
\text { e infantil }\end{array}$ & $\begin{array}{c}\text { Escenario } \\
\text { de } \\
\text { estancia } \\
\text { y } \\
\text { deportivo }\end{array}$ & $\begin{array}{c}\text { Escenario } \\
\text { de } \\
\text { estancia, } \\
\text { infantil y } \\
\text { deportivo }\end{array}$ \\
\hline Vecinal & 11 & 10 & 11 & 14 & 11 & 13 & 14 \\
\hline $\begin{array}{c}\text { Zonal - } \\
\text { Regional }\end{array}$ & 13 & 12 & 13 & 16 & 13 & 15 & 16 \\
\hline
\end{tabular}

Fuente: Elaboración propia.

En síntesis, el porcentaje de déficit cualitativo se calcula para cada uno de los elementos del espacio público existentes en la ciudad, permitiendo su espacialización y la identificación de áreas donde la calidad de vida urbana se ve afectada por el mal estado de los mismos, la presión o sobreutilización.

Determinación del déficit cualitativo en la parte occidental de la ciudad de Montería. Calculado el déficit cualitativo en cada uno de los escenarios deportivos, infantiles y de estancia, con base en la valoración de los elementos del espacio público, es posible representar esta variable cartográficamente (Figura 1).

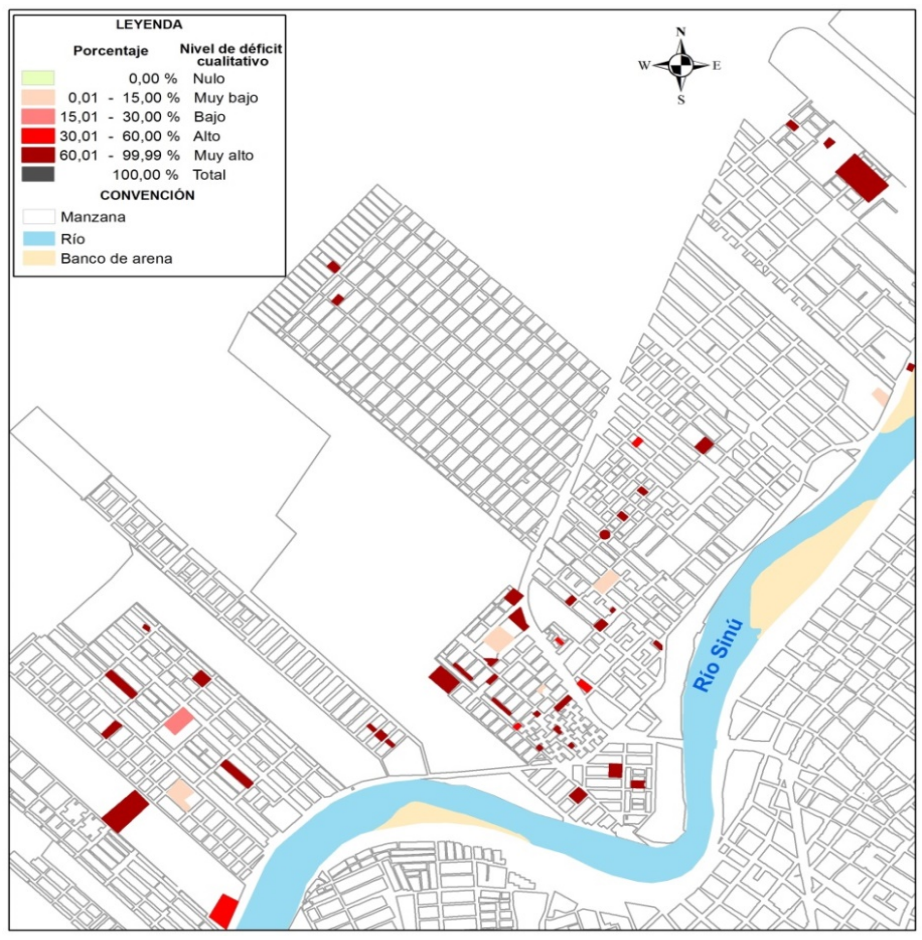

Figura 1. Mapa de déficit de espacio público en el occidente de la ciudad de Montería.

Fuente: Elaboración propia. 
Déficit nulo: escenarios de espacio público que se encuentran sin déficit cualitativo, es decir, 0,00\%. Incluyen aspectos de arborización o sombra, inexistencia de invasión, buen estado del mobiliario o componente interno. Para el caso de la parte occidental de la ciudad de Montería, ningún escenario presenta este porcentaje de déficit (Figura 1).

Muy bajo déficit: escenarios con un déficit cualitativo representado entre el $0,01 \%$ y el $15,00 \%$, asociado con la ausencia o deterioro de algunos mobiliarios o componentes internos que no forman parte de los componentes principales, lo que no logra afectar el funcionamiento de los mismos. Se delimitó este déficit en cinco de 51 elementos existentes en el occidente de la ciudad de Montería, predominando los escenarios de estancia en combinación con los infantiles, siendo tres de escala zonal y dos escala vecinal, registrándose entre una y dos condiciones generadoras de déficit de acuerdo con el tipo de escenario de espacio público, entre las que pueden estar la ausencia de luminarias, canecas, algún tipo de invasión (basuras, vehicular u otra) o que no esté incluido en algún plan para la creación, potenciación y reparación de sus elementos.

Bajo déficit: corresponde a escenarios de espacio público con porcentajes de déficit cualitativo que oscila entre el $15,01 \%$ y el $30,00 \%$, con un porcentaje mayor de ausencia o deterioro de algunos mobiliarios o componentes internos que no son parte de los componentes principales en comparación con la categoría anterior, sin afectar el funcionamiento de estos. Se delimitó este déficit en uno de 51 elementos existentes en el occidente de la ciudad de Montería, siendo un escenario deportivo con cobertura vecinal, registrándose entre dos y cuatro condiciones generadoras de déficit, dependiendo del tipo de escenario de espacio público y la escala o área de influencia del mismo, por ausencia de luminarias, canecas, existencia de algún tipo de invasión (basuras, vehicular u otra) y o que esté excluido de algún plan para la creación, potenciación y reparación de sus elementos.

Alto déficit: son aquellos elementos de espacio público que están siendo sometidos a la presión y sobreutilización por parte de los ciudadanos, generando porcentajes de déficit cualitativo en el rango $30,01 \%-60,00 \%$. Tal es el caso de los escenarios deportivos y estancia, cinco de 51, principalmente los primeros (cuatro de cinco), evidenciando valores porcentuales que demuestran el mal estado de dichos elementos, que particularmente existen en la parte occidental de la ciudad de Montería, cuya cobertura o área de influencia en su mayoría es zonal (tres de cinco) y en menor cantidad vecinal (dos de cinco), observándose entre cuatro y nueve condiciones generadoras de déficit cualitativo de acuerdo con el tipo de escenario de espacio público y la escala o área de influencia del mismo. Se caracterizan por la falta de luminarias, canecas, presencia de algún tipo de invasión (basuras, vehicular u 
otra) y/o estar por fuera de algún plan para la creación, potenciación y reparación de sus elementos.

Esta categoría de déficit evidencia la necesidad de intervención y actuación sobre los elementos constitutivos del espacio público, así como en la prestación de las funciones del mismo en cuanto al goce, disfrute, integración, articulación, descanso, ocio, práctica del deporte, entre otras.

Muy alto déficit: esta se refiere al déficit cualitativo de los elementos de espacio público entre porcentajes del $60,01 \%$ y el $99,99 \%$. Esta exige de forma prioritaria, desde la planificación, la gestión y el ordenamiento territorial, la adecuación, intervención y mejoramiento del mobiliario urbano de los componentes principales. Refleja el mal estado de sus elementos y con ello la disfuncionalidad del espacio público en la ciudad, evidenciando uno de los valores porcentuales con mayor número de elementos en mal estado. Se ven afectadas las funciones del espacio público al encontrarse en mal estado el mobiliario urbano de sus componentes principales, por ejemplo, en escenarios deportivos el campo o terreno de juego, los arcos, las cestas, las mallas, entre otros; en infantiles (módulos infantiles) y de estancia (bancas y sombras).

En la parte occidental de la ciudad de Montería, sobresalen mayoritariamente 40 escenarios de 51 en total, de los cuales predominan los escenarios de estancia por encima de los deportivos e infantiles, cuya cobertura predominante es la vecinal (35 de 40) sobre la zonal (cinco restantes), observándose de siete a 15 condiciones generadoras de déficit cualitativo, a lo que se suma el deterioro o mal estado de uno de sus componentes principales.

Déficit total: escenarios de espacio público con déficit cualitativo en la totalidad de sus elementos, es decir, $100,00 \%$, lo que evidencia el estado crítico de los mismos y la necesidad de intervenciones y actuaciones urgentes desde la planeación y el ordenamiento territorial de las ciudades. En el costado occidental de la ciudad de Montería, ningún escenario presenta este porcentaje de déficit.

\footnotetext{
Algunas consideraciones acerca del diseño y aplicación de la metodología para la medición del déficit cualitativo de espacio público. La tabla o formato para la recolección de datos en campo sobre las condiciones que generan déficit cualitativo en el espacio público, además de facilitar la cálculo del porcentaje de déficit, se convierte en una importante fuente de datos, funcional para los tomadores de decisión encargados de la reparación y potenciación del espacio público, puesto que esta identifica todos los aspectos que están generando déficit en cada elemento del espacio público existente en la ciudad. Los datos disponibles en dicho formato pueden ser recolectados y diligenciados, no solo por un único funcionario representante de la administración municipal, sino también por la comunidad usuaria del espacio
} 
público, ya que presenta un diseño que lo hace viable para ser incorporado e implementado en un Sistema de Información Geográfico participativo, que involucre a la comunidad en los procesos de planificación y ordenamiento de las ciudades.

Con el caso aplicado en el occidente de la ciudad de Montería se demostró que la calidad de vida urbana se ve afectada por el mal estado físico en que se encuentra el espacio público existente, toda vez que las funciones que presta a la comunidad no logran prestarse de manera óptima. El espacio público en esta parte de la ciudad se compone en su mayoría por escenarios de estancia con déficit muy alto (61,00 \% a $99 \%)$, lo que expresa un espacio que demanda de urgentes acciones de planificación, gestión y ordenamiento territorial que intervengan sobre sus componentes internos, en aras de garantizar el acceso, uso y disfrute, promoviendo sus funcionalidades. Estos valores porcentuales máximos registran problemas de mobiliario urbano tanto de sus componentes principales como en el resto, demostrando el mal estado o deterioro de sus elementos.

En la actualidad las ciudades reflejan la necesidad de disponer de espacios públicos de calidad, los cuales deben ser valorados a partir de los déficit cualitativo y cuantitativo como indicadores que dan cuenta de su estado y, dependiendo de su línea de base, orientan la ejecución de programas y proyectos que materializan su mejoramiento, generación y recuperación.

Cabe resaltar que en la ciudad de Montería el Plan de Ordenamiento Territorial (2002-2015), que fue revisado y ajustado en el año 2010, se logró calcular estos déficit en el área urbana, tomando como base la metodología que se presentó en este artículo, de tal modo que la Alcaldía, las Secretarías de Planeación e Infraestructura y las empresas prestadoras de servicios públicos domiciliarios están llamadas a dar respuesta para reducirlos.

\section{Conclusiones}

El cálculo del déficit cualitativo de espacio público constituye un instrumento metodológico que puede ser de gran ayuda en los procesos de planificación, gestión y ordenamiento territorial, puesto que este proporciona en términos cualitativos las condiciones o estado físico de este atributo urbano por incluir en los diagnósticos de los planes de ordenamiento territorial, lo cual permite su intervención (Roberts, 2005). Es un soporte para los procesos de ordenamiento territorial urbano que se adelantan actualmente en Colombia con la segunda generación de planes de ordenamiento territorial. La primera fue después de la aprobación y adopción de la Ley 388 de 1997, mediante la cual se reglamenta el ordenamiento territorial municipal, la cual presenta aún grandes vacíos funcionales. 
Los aspectos que se consideran para la evaluación del déficit cualitativo de espacio público (Tabla 3 ) se soportan en la clasificación del espacio público según la composición y función que presta a la comunidad, así como la escala o área de influencia. Dichas clasificaciones abordan la mayoría de tipologías de espacio público existentes en las ciudades, tales como: parques, las rondas hídricas, zonas verdes, canchas deportivas, plazas y plazoletas, entre otros. No obstante, en algunas ciudades, existen parques temáticos con características únicas y especiales, dotados de equipamientos y mobiliario poco común, que los hacen llamativos para usuarios locales y residentes en zonas distantes. Entre estos se pueden mencionar los parques zoológicos y los parques de atracciones mecánicas de libre acceso a la comunidad. Ante estos casos, se debe adicionar en el formato de recolección de datos in situ para la medición del déficit, algunos ítems que permitan valorar los equipamientos, mobiliarios o componentes internos de estas tipologías de espacio público que, hasta el momento, no han sido considerados en la presente metodología. Lo anterior obliga también a precisar el número de condiciones mínimas requeridas para evaluar dichos espacios.

A pesar de que el Municipio de Montería cuenta con un plan de ordenamiento territorial, las condiciones cualitativas del espacio público no son las mejores, como muestra el registro de la mayoría de los escenarios en déficit muy alto, sin que se tomen decisiones a partir del diagnóstico que en este se plantearon. El caso de estudio aplicado en este artículo revela que, en el occidente de la ciudad, hay problemas críticos a nivel del espacio público, donde la categoría "muy alto déficit cualitativo", representando en el rango porcentual entre el $61,00 \%$ y el 99,00\%, está en 40 de 51 elementos existentes. La tabla o formato de recolección diligenciada en campo muestra que estos problemas son causados por la ausencia de sombra, así como por el mal estado de luminarias, bancas, módulos infantiles, graderías, campo o terreno de juego en escenarios deportivos, múltiples formas de invasión, entre otros. Los resultados del caso de estudio suministran importantes datos que sirven de base para la adecuada planificación y gestión del espacio público en la margen izquierda de la ciudad.

El espacio público debe concebirse como un elemento estructurador del territorio, que logre la articulación e integración de la ciudadanía y la ciudad (Salcedo, 2002), para lo cual se requiere comprender como un sistema en el cual se conjugan múltiples variables físico-espaciales, socioculturales y políticas (Rizzo, 2010; Van Kamp, Leidelmeijer, Marsman \& De Hollander, 2003). En este sentido, la presente investigación aporta lineamientos metodológicos acerca de la determinación del déficit cualitativo de espacio público en Colombia como indicador de calidad de vida urbana, necesaria para desarrollar las políticas de ciudades y, a su vez, de ordenamiento territorial. El déficit cualitativo es solo un elemento de análisis de los muchos otros que se deben considerar para efectuar diagnósticos profundos que revelen la 
verdadera situación actual de las ciudades, con el fin de ejercer una óptima panificación. El análisis del déficit cuantitativo, la distribución del espacio público en el territorio y la diversidad en función de los intereses, gustos y preferencias de la población citadina son, entre muchos otros, aspectos clave que se complementan.

Por su parte, las condiciones físico-espaciales del espacio público que son descritas y valoradas estadísticamente a través de la medición del déficit cualitativo dejan ver la preocupación por indagar acerca de las posibilidades de articulación como instrumento de planificación y ordenamiento territorial presentes en Colombia. Continuar con la valoración de la sostenibilidad del espacio público como parte del proceso de planeación en la cual la participación ciudadana y la cogestión entre el Estado y las comunidades demuestren un vínculo estrecho, es de gran importancia. Para esto, se requiere de la concepción del espacio público desde la dimensión sociocultural (Rincón, 2010) a partir de la cual se concibe el lugar de la relación, el encuentro entre las personas, movimiento y sentido comunitario, convergiendo los conceptos de espacio y lugar para definir el espacio público. 


\section{Referencias bibliográficas}

Borja, J. (1998). Ciudadanía y espacio público. Revista Ambiente y Desarrollo, $14(3), 13-22$.

Borja, J. y Muxi, Z. (2000). El espacio público, ciudad y ciudadanía. Recuperado de http://www.esdionline.com/repositori/public/dossiers/DIDAC_wdw7ydy1.pdf

Carmona, M., Health, T., Oc, T., \& Tiesdell, S. (2003). Public places urban spaces the dimensions of urban design. Oxford: Architectural Press.

Consejo Nacional de Política Económica y Social, Conpes. (2012). Política Nacional de Espacio Público. Recuperad de http://www.minvivienda.gov.co/POTPresentacionesGuias/Guía Formulación Planes Ordenamiento.pdf

Daza, W. (2008). La intervención en el espacio público como estrategia para el mejoramiento de la calidad de vida urbana. Caso de estudio Valle de Laboyos (Pitalito-Huila) (Tesis de maestría en Planeación Urbana y Regional). Pontificia Universidad Javeriana, Bogotá, Colombia.

Garnica, R. (2009). Análisis de la estructura urbana de Montería. Configuración espacial de la ciudad. Córdoba: Departamento de Geografía y Medio Ambiente, Universidad de Córdoba.

Garnica, R. y Jiménez, J. (2013). La calidad de vida urbana y la dimensión físico-espacial del espacio público: aportes metodológicos para el ordenamiento territorial de Montería. Revista Perspectiva Geográfica, 18(2), 257-280. https://dx.doi.org/10.19053/01233769.2678

Garriz, E. y Scroeder, R. (2014). Dimensiones del espacio público y su importancia en el ámbito urbano. Revista Científica Guillermo de Ockham, 12(2), 25-30. https://doi.org/10.21500/22563202.59

Giraldo, F. (1989). Espacio público y lugar. En F. Giraldo (Ed.), Ciudad y complejidad (pp. 76-93). Bogotá: Fundación para la Investigación y la Cultura FICA.

Hebbert, M. (2005). The street as locus of collective memory. Society and Space, 23(4), 581-596. https://doi.org/10.1068/d55j

Inzulza-Contardo, J. \& Cruz, C. (2014). Civic design: Incorporating urbanity and sustainability from the roots of Chilean society. Geography Compass, 8(12), 860-873. https://doi.org/10.1111/gec3.12185 
Inzulza-Contardo, J. (2014). La recuperación del diseño cívico como reconstrucción de lo local en la ciudad intermedia: el caso de Talca, Chile. Revista AUS, 15, 4-8. https://doi.org/10.4206/aus.2014.n15-02

Jiménez, J. (2009). Espacio público y calidad de vida urbana: análisis de las condiciones físico-espaciales en la ciudad de Montería. Córdoba: Departamento de Geografía y Medio Ambiente, Universidad de Córdoba.

Martí, P., García, S., y Nolasco, A. (2013). Movilidad, espacio público y arquitectura. $\quad A R Q$ (Santiago), 85, 24-33. https://dx.doi.org/10.4067/S0717-69962013000300005

Ministerio de Vivienda, Ambiente y Desarrollo Territorial. (2004). Guía metodológica 1 Información práctica para formulación Planes de Ordenamiento Territorial. Santa Fe de Bogotá: Ministerio de Vivienda, Ambiente y Desarrollo Territorial.

Monnet, N. (2000). El uso del espacio público por parte de los nuevos habitantes del casc antic de Barcelona: continuidad e innovaciones. Scripta Nova, 69(48). http://www.ub.edu/geocrit/sn-69-48.htm

Páramo, P. (2007). El significado de los lugares públicos para la gente de Bogotá. Bogotá, Universidad Pedagógica Nacional.

Páramo, P. y García, M. (2010). La dimensión social del espacio público. Aportes para la calidad de vida urbana. Bogotá: Universidad Pedagógica Nacional y Universidad Santo Tomás de Aquino.

Rincón, I. (2010). Experiencias urbanas en jóvenes: una posibilidad para el aprendizaje. Bogotá: Universidad Pedagógica Nacional.

Rizzo, P. (2010). El espacio público de la ciudad de Mendoza (Argentina), Espacio de Disputa y Expresión Ciudadana. ACME: An International EJournal for Critical Geographies, 9(2), 164-190. Recuperado de http://ojs.unbc.ca/index.php/acme/article/viewFile/865/721

Roberts, B. (2005). Globalization and Latin American cities. International Journal of Urban and Regional Research, 29(1), 110-123.

Salcedo, R. (2002). El espacio público en el debate actual: una reflexión crítica sobre el urbanismo post-moderno. Eure (Santiago), 28(84), 5-19. https://dx.doi.org/10.4067/S0250-71612002008400001 
Saldarriaga, A. (2005, 14 de agosto). Entrevista concedida al periódico de la Universidad Nacional (UNP No 79). Recuperado de http://historico.unperiodico.unal.edu.co/ediciones/79/04.htm

Sequera, J. y Janoschka, M. (2012). Ciudadanía y espacio público en la era de la globalización neoliberal. Arbor, 188(755), 515-527. http://dx.doi.org/10.3989/arbor.2012.755n3005

Schurch, T. W. (1999). Reconsidering urban design: Thoughts about its definition and status as a field or profession. Journal of Urban Design, 4(1), 5-28. https://doi.org/10.1080/13574809908724436

Stephens, A. (2010). Citizenship without community. Citizenship Studies, 14(1), 31-46. https://doi.org/10.1080/13621020903466282

Van Kamp, I., Leidelmeijer, K., Marsman, G., \& De Hollander, A. (2003). Urban environmental quality and human wellbeing. Towards a conceptual framework and demarcation of concepts; a literature study. Landscape and Urban Planning, 65(1-2), 5-18. https://doi.org/10.1016/s01692046(02)00232-3 